\title{
Effects of Nonequilibrium Chemistry and Darcy-Forchheimer Pyrolysis Flow for Charring Ablator
}

\author{
Yih-Kanq Chen* and Frank S. Milos ${ }^{\dagger}$ \\ NASA Ames Research Center, Moffett Field, California 94035-1000
}

DOI: $10.2514 / 1 . A 32289$

\begin{abstract}
The fully implicit ablation and thermal response code simulates pyrolysis and ablation of thermal protection materials and systems. The governing equations, which include energy conservation, a three-component decomposition model, and a surface energy balance, are solved with a moving grid. This work describes new modeling capabilities that are added to a special version of code. These capabilities include a time-dependent pyrolysis gas flow momentum equation with Darcy-Forchheimer terms and pyrolysis gas species conservation equations with finiterate homogeneous chemical reactions. The total energy conservation equation is also enhanced for consistency with these new additions. Two groups of parametric studies of the phenolic impregnated carbon ablator are performed. In the first group, an Orion flight environment for a proposed lunar-return trajectory is considered. In the second group, various test conditions for arcjet models are examined. The central focus of these parametric studies is to understand the effect of pyrolysis gas momentum transfer on material in-depth thermal responses with finite-rate, equilibrium, or frozen homogeneous gas chemistry. Results indicate that the presence of chemical nonequilibrium pyrolysis gas flow does not significantly alter the in-depth thermal response performance predicted using the chemical equilibrium gas model.
\end{abstract}

\begin{tabular}{ll} 
& \multicolumn{1}{c}{ Nomenclature } \\
$b$ & $=$ permeability slip parameter, Pa \\
$B_{a}$ & $=$ preexponential constant, $\mathrm{s}^{-1}$ \\
$B^{\prime}$ & $=\dot{m} / \rho_{e} u_{e} C_{M}$, dimensionless mass-blowing rate \\
$C_{F}$ & $=$ Forchheimer coefficient \\
$C_{H}, C_{M}$ & $=$ Stanton numbers for heat and mass transfer \\
$c_{i}$ & $=$ mass fractions of species $i$ \\
$c_{p}$ & $=$ specific heat, $\mathrm{J} / \mathrm{kg} \cdot \mathrm{K}$ \\
$D$ & $=$ diffusion coefficient, $\mathrm{m}^{2} / \mathrm{s}$ \\
$d_{p}$ & $=$ diameter of pore, $\mathrm{m}$ \\
$E$ & $=$ total internal energy, $\mathrm{J} / \mathrm{kg}$ \\
$e$ & $=$ internal energy, $\mathrm{J} / \mathrm{kg}$ \\
$E_{a}$ & $=$ activation energy, $\mathrm{J} / \mathrm{kmol}$ \\
$H$ & $=$ total enthalpy, $\mathrm{J} / \mathrm{kg}$ \\
$h$ & $=$ enthalpy, $\mathrm{J} / \mathrm{kg}$ \\
$H_{r}$ & $=$ recovery enthalpy, $\mathrm{J} / \mathrm{kg}$ \\
$h_{w}$ & $=$ wall enthalpy, $\mathrm{J} / \mathrm{kg}$ \\
$K$ & $=$ permeability, $\mathrm{m}^{2}$ \\
$k$ & $=$ thermal conductivity, $\mathrm{W} / \mathrm{m} \cdot \mathrm{K}$ \\
$K_{0}$ & $=$ permeability in the limit of continuum flow, $\mathrm{m}^{2}$ \\
$k_{b}$ & $=$ backward reaction rate \\
$k_{f}$ & $=$ forward reaction rate \\
$M$ & $=$ molecular mass, $\mathrm{g} / \mathrm{mol}$ \\
$m$ & $=$ total number of homogeneous reactions \\
$\dot{m}$ & $=$ mass flux, $\mathrm{kg} / \mathrm{m}^{2} \cdot \mathrm{s}$ \\
$N_{s}$ & $=$ total number of chemical species \\
$p$ & $=$ pressure, Pa \\
$q_{\mathrm{cw}}$ & $=$ conductive heat flux at surface, $\mathrm{W} / \mathrm{m}^{2}$ \\
$q_{\mathrm{rw}}$ & $=$ radiative heat flux at surface, $\mathrm{W} / \mathrm{m}^{2}$ \\
$R$ & $=$ universal gas constant $\mathrm{J} / \mathrm{kmol} \cdot \mathrm{K}$ \\
$R$ & $=$ gas constant, $\mathrm{J} / \mathrm{kg} \cdot \mathrm{K}$ \\
&
\end{tabular}

Presented as Paper 2011-3122 at the 42nd Thermophysics Conference, Honolulu, Hawaii, 28-30 June 2011; received 8 December 2011; revision received 5 March 2012; accepted for publication 2 May 2012; published online 23 November 2012. Copyright (C 2012 by the American Institute of Aeronautics and Astronautics, Inc. All rights reserved. Copies of this paper may be made for personal or internal use, on condition that the copier pay the $\$ 10.00$ per-copy fee to the Copyright Clearance Center, Inc., 222 Rosewood Drive, Danvers, MA 01923; include the code 1533-6794/12 and \$10.00 in correspondence with the CCC.

*Aerospace Engineer, Aerothermodynamics Branch, MS 230-2. Member AIAA.

${ }^{\dagger}$ Aerospace Engineer, Thermal Protection Materials Branch, MS 234-1. Senior Member AIAA.

\begin{tabular}{|c|c|c|}
\hline$\dot{R}_{\mathrm{di}}$ & $=$ & $\begin{array}{l}\text { mass generation rate of gas species } i \text { due to resin } \\
\text { decomposition, } \mathrm{kg} / \mathrm{m}^{3} \cdot \mathrm{s}\end{array}$ \\
\hline$\dot{R}_{i}$ & $=$ & $\begin{array}{l}\text { mass generation rate of gas species } i \text { due to } \\
\text { homogeneous reactions, } \mathrm{kg} / \mathrm{m}^{3} \cdot \mathrm{s}\end{array}$ \\
\hline$R e_{d}$ & $=$ & pore diameter-based Reynolds number \\
\hline$T$ & $=$ & temperature, $\mathrm{K}$ \\
\hline$t$ & $=$ & time, $\mathrm{s}$ \\
\hline$u$ & $=$ & local gas velocity, $\mathrm{m} / \mathrm{s}$ \\
\hline$v$ & $=$ & local grid velocity, $\mathrm{m} / \mathrm{s}$ \\
\hline$\alpha$ & $=$ & surface absorptance \\
\hline$\Gamma$ & $=$ & volume fraction of resin \\
\hline$\varepsilon$ & $=$ & porosity \\
\hline$\varepsilon_{w}$ & $=$ & surface emissivity \\
\hline$\lambda$ & $=$ & blowing reduction parameter \\
\hline$\mu$ & $=$ & viscosity, $\mathrm{N} \cdot \mathrm{s} / \mathrm{m}^{2}$ \\
\hline$\rho$ & $=$ & total density, $\mathrm{kg} / \mathrm{m}^{3}$ \\
\hline$\rho_{o}$ & $=$ & original density of pyrolysis gas component, $\mathrm{kg} / \mathrm{m}^{3}$ \\
\hline$\rho_{r}$ & $=$ & residual density of pyrolysis gas component, $\mathrm{kg} / \mathrm{m}^{3}$ \\
\hline$\sigma$ & $=$ & Stefan-Boltzmann constant, $\mathrm{W} / \mathrm{m}^{2} \cdot \mathrm{K}^{4}$ \\
\hline$\tau$ & $=$ & mass fraction of virgin material, defined in Eq. (11) \\
\hline$\Psi$ & $=$ & decomposition reaction order \\
\hline
\end{tabular}

Subscripts

$\begin{array}{ll}c & =\text { char } \\ e & =\text { boundary-layer edge } \\ g & =\text { pyrolysis gas } \\ i & =\text { density component }(\mathrm{A}, \mathrm{B}, \text { and } \mathrm{C}) \text { or gas species } \\ j & =\text { surface species } \\ v & =\text { virgin } \\ w & =\text { wall }\end{array}$

\section{Introduction}

$\mathbf{T}$ HE authors have developed a family of programs for analysis of ablative thermal protection system (TPS) materials. The fully implicit ablation and thermal response code (FIAT) [1], the twodimensional implicit thermal response and ablation code (TITAN) [2], and the three-dimensional finite-volume alternating direction implicit ablation and thermal response code (3dFIAT) [3] simulate the internal heat conduction, in-depth thermal decomposition, quasisteady pyrolysis gas flow, and surface ablation of TPS materials in one, two, and three dimensions, respectively. FIAT is widely used by NASA and the industry as the one-dimensional analysis and sizing 
Table 1 List of pyrolysis gas chemical reactions and rates

\begin{tabular}{|c|c|c|c|c|c|}
\hline Reaction number & Reaction formula & Rate law & $E, \mathrm{Kcal} / \mathrm{g} \cdot \mathrm{mol}$ & $\mathrm{A}$, mole $/ m^{3} \cdot s$ & $\underline{s}$ \\
\hline 1 & $2 \mathrm{CH}_{4} \quad \mathrm{C}_{2} \mathrm{H}_{6}+\mathrm{H}_{2}$ & $k_{f}\left[\mathrm{CH}_{4}\right]$ & 95 & $7.6 \times 10^{14}$ & 0 \\
\hline 2 & $\mathrm{C}_{2} \mathrm{H}_{6} \quad \mathrm{C}_{2} \mathrm{H}_{4}+\mathrm{H}_{2}$ & $k_{f}\left[\mathrm{C}_{2} \mathrm{H}_{6}\right]$ & 70 & $3.1 \times 10^{14}$ & 0 \\
\hline 3 & $\mathrm{C}_{2} \mathrm{H}_{4} \quad \mathrm{C}_{2} \mathrm{H}_{2}+\mathrm{H}_{2}$ & $k_{f}\left[\mathrm{C}_{2} \mathrm{H}_{4}\right]$ & 40 & $2.6 \times 10^{8}$ & 0 \\
\hline 4 & $\mathrm{C}_{2} \mathrm{H}_{2} \quad 2 \mathrm{C}+\mathrm{H}_{2}$ & $k_{f}\left[\mathrm{C}_{2} \mathrm{H}_{2}\right]^{2}$ & 10 & $2.1 \times 10^{10}$ & 0 \\
\hline 5 & $\mathrm{C}+2 \mathrm{H}_{2} \quad \mathrm{CH}_{4}$ & $k_{f}$ & 17 & $2.0 \times 10^{9}$ & 0 \\
\hline 6 & $\mathrm{C}+\mathrm{H}_{2} \mathrm{O} \quad \mathrm{CO}+\mathrm{H}_{2}$ & $k_{f}[\mathrm{C}]\left[\mathrm{H}_{2} \mathrm{O}\right]$ & 82 & $1.2 \times 10^{12}$ & -1 \\
\hline 7 & $\mathrm{CO}+\mathrm{H}_{2} \mathrm{O} \quad \mathrm{H}_{2}+\mathrm{CO}_{2}$ & $k_{f}[\mathrm{CO}]\left[\mathrm{H}_{2} \mathrm{O}\right]$ & 30 & $1.0 \times 10^{12}$ & 0 \\
\hline 8 & $\mathrm{C}+\mathrm{CO}_{2} \quad 2 \mathrm{CO}$ & $k_{f}[\mathrm{C}]$ & 50 & $1.0 \times 10^{6}$ & -1 \\
\hline 9 & $2 \mathrm{CO} \quad \mathrm{C}+\mathrm{CO}_{2}$ & $k_{f}[\mathrm{CO}]^{2}$ & 61 & $1.0 \times 10^{-9}$ & 0 \\
\hline
\end{tabular}

tool for spacecraft TPS materials. TITAN can analyze problems with two-dimensional or axisymmetric geometry. In some cases, a twodimensional analysis is inadequate, and a three-dimensional ablation code is required to perform a high-fidelity simulation. The 3dFIAT program can analyze the thermal response of the entire heat shield of a space vehicle. The prediction of ablative heat shield response for a spacecraft entering the atmosphere with an angle of attack is such a case.

In this family of programs, decomposing materials are assumed to behave as three independently pyrolyzing components. Once the pyrolysis gas is formed, the gas flow is assumed to reach steady state instantaneously by ignoring the pressure and viscous resistance effects. These assumptions are generally good if the char depth is relatively thin. In such cases, there is no need to solve the momentum and species conservation equations for pyrolysis gas flow.

The nonequilibrium chemistry of pyrolysis gas inside the char layer was first studied by April et al. in 1971 [4]. Since then, there have been no significant efforts made in this area to model the finiterate homogeneous chemical reactions of pyrolysis gas. Recently, a study conducted by Ayasoufi et al. attempted to examine the effect of nonequilibrium pyrolysis gas chemistry on the performance of charring ablators [5], in which the pyrolysis gas chemistry was based on the work of April et al. [4]. However, in the work by Ayasoufi et al. [5], the gas flow momentum conservation was not considered, and thus, the mass flow rate and kinetic energy of the gas could not be accurately predicted. The effect of permeability on gas flow inside a charring ablator was extensively studied by Ahn et al. [6]. They solved the gas momentum equation within a carbon-phenolic heat shield of the Pioneer Venus probes for pyrolysis gas in chemical equilibrium. Recently, the non-Darcy behavior of pyrolysis gas in a thermal protection system also was examined by Martin and Boyd [7].

Given the large surface area within porous TPS materials, one would think that both homogeneous (gas) and heterogeneous (surface) reactions may be important for how quickly pyrolysis gas approaches a state of chemical equilibrium. Heterogeneous reactions are important for additional complex phenomena, such as coking, which was observed in the Apollo heat shield [8]. However, the effect of heterogeneous reactions within pyrolyzing heat shields has been mostly neglected.

Darcy's law has limited applicability, because it only accounts for the viscous resistance of the flow at a low speed. If the flow speed is not sufficiently low, then inertial contributions to the flow resistance may become noticeable. The Darcy-Forchheimer equation [9] is widely used to account for the inertial effects in porous media. In this paper, we enhanced the FIAT code by including the time-dependent pyrolysis gas momentum equation with the Darcy-Forchheimer terms within a porous char layer to obtain the flow velocity. Additionally, the multispecies mass conservation equations for pyrolysis gas are solved to simulate the nonequilibrium chemistry that may occur inside a char layer. The three-component decomposition model, which is based on the thermogravimetric analysis (TGA) data, is used to estimate the instantaneous density of resin. For nonequilibrium pyrolysis gas modeling, the homogeneous chemical reactions and associated rates similar to those developed by April et al. [4] are considered.

The charring thermal protection material considered in this work is the phenolic impregnated carbon ablator (PICA) [10], which is a low- density ablator that was used as the heat-shield material of the Stardust sample return capsule [11]. The purpose of this paper is twofold: first, to describe the details of the formulation considered in the enhanced version of FIAT; and second, to perform parametric studies to understand how the pyrolysis gas momentum transfer affects PICA material in-depth thermal response with various gas chemistry models to guide the direction of future work. The aerothermal environments used for the parametric studies are those relevant to the Orion Lunar return mission, including both flight and arcjet conditions. The predictions are presented and compared with those based on the PICA/FIAT material response model developed by the Orion Thermal Protection System Advanced Development Project (TPS ADP) [12].

\section{Governing Equations}

Under the assumption of local thermal equilibrium, the total energy conservation equation in conservative form for the combined solid-gas system inside a charring ablator is defined as

$$
\begin{aligned}
& \frac{\partial}{\partial t}\left(\rho c_{p} T+\varepsilon E_{g}\right)+\nabla \cdot\left(\varepsilon \mathbf{u}_{g} H_{g}\right)+\nabla \cdot \\
& \quad=\mathbf{v} \cdot \nabla\left(\rho c_{p} T+\varepsilon E_{g}\right)
\end{aligned}
$$

where

$$
\begin{gathered}
E_{g}=\sum_{i=1}^{N_{s}} \rho_{i} e_{i}+\frac{1}{2} \rho_{g} u_{g}^{2} \quad H_{g}=\sum_{i=1}^{N_{s}} \rho_{i} h_{i}+\frac{1}{2} \rho_{g} u_{g}^{2} \\
p=\left(\sum_{i=1}^{N_{s}} \rho_{i} R_{i}\right) T=\rho_{g} R_{g} T \quad \rho_{g}=\sum_{i=1}^{N_{s}} \rho_{i}
\end{gathered}
$$

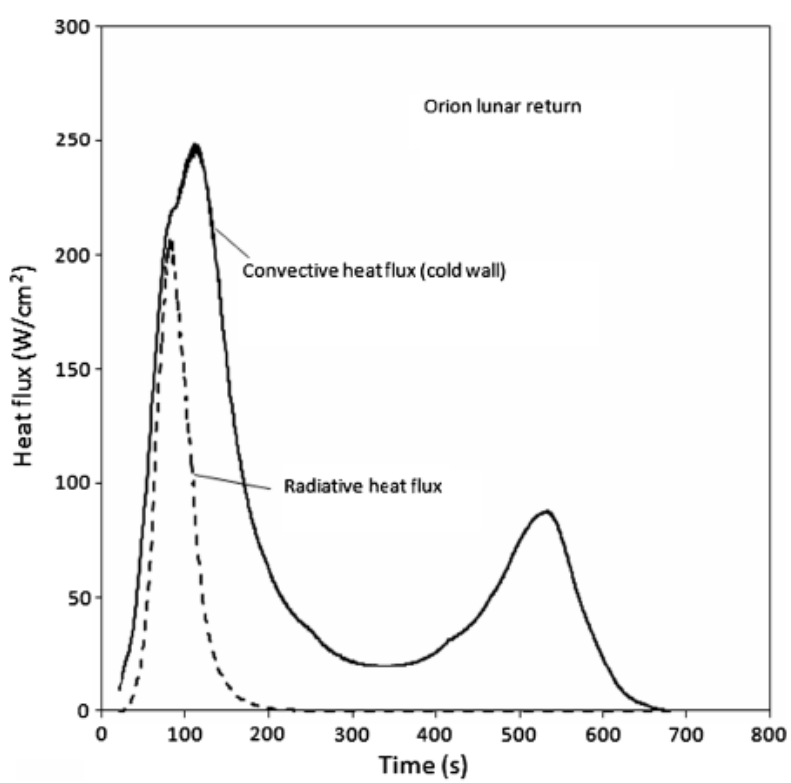

Fig. 1 Aerothermal environment for group I. 


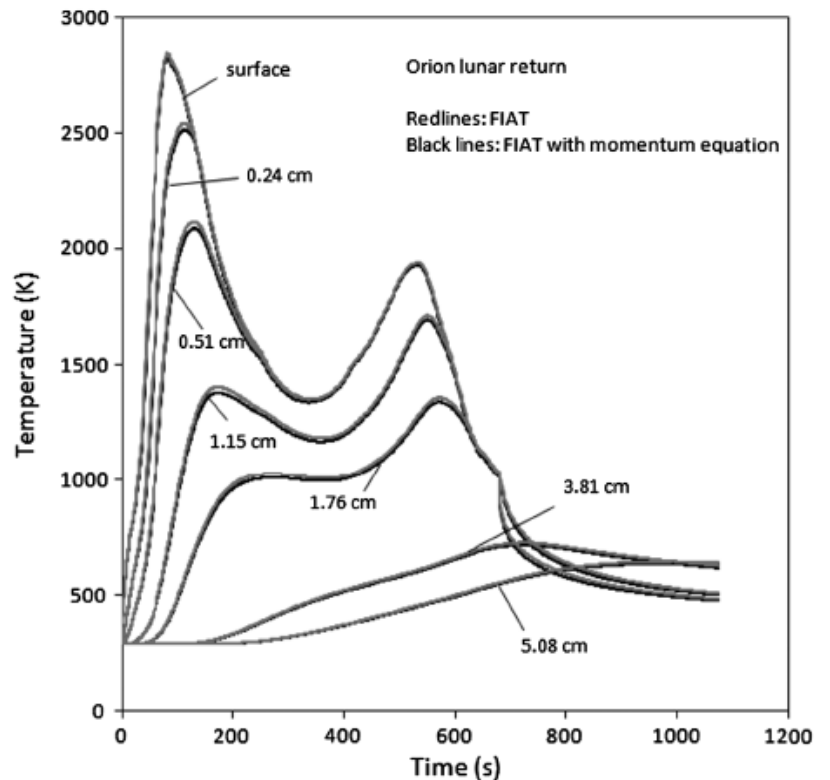

Fig. 2 Surface and in-depth temperatures predicted by baseline FIAT and by FIAT with momentum equation.

The individual terms in Eq. (1) are interpreted as follows: rate of storage of total internal energy, net rate of total enthalpy convected by gas flow, net rate of thermal conductive heat flux, and convection rate of total internal energy due to coordinate system movement. The conductivity of pyrolysis gas is much smaller than that of the solid, and thus, the conductive heat flux through the gas is ignored. If the internal energy, $\rho_{i} e_{i}$, and the kinetic energy, $\frac{1}{2} \rho_{g} u_{g}^{2}$, of gas flow are ignored, then Eq. (1) reduces to the same form used in the previous work [1].

Darcy's law is applicable to low-speed flows, such as the modeling of underground flows. Typically, this means that the Reynolds number, based on the average pore diameter, has an order of magnitude near unity or less:

$$
R e_{d}=\frac{\rho_{g} u_{g} d_{p}}{\mu_{g}}=O(1)
$$

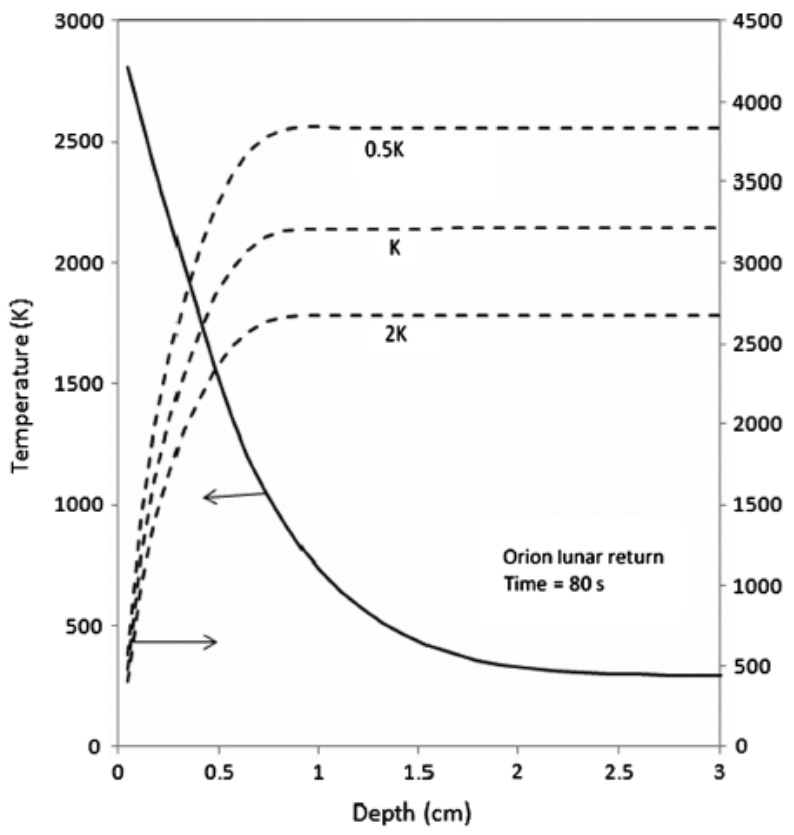

a)

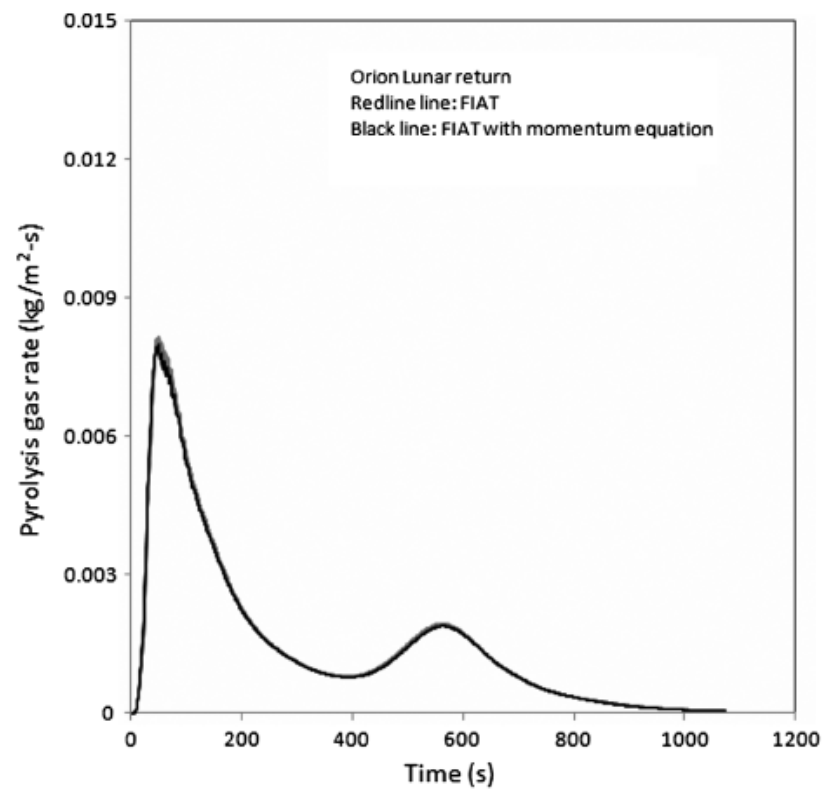

Fig. 3 Pyrolysis gas mass injection rate predicted by baseline FIAT and by FIAT with momentum equation.

Darcy's law only accounts for the viscous resistance of the flow. As the flow velocity is increased, inertial terms also should be considered. The Darcy-Forchheimer equation is widely used to account for the inertial effects. The transient Darcy-Forchheimer equation adopted in this work to predict the pyrolysis gas flow velocity is written as

$$
\begin{aligned}
& \frac{\partial \varepsilon \rho_{g} \mathbf{u}_{g}}{\partial t}+\nabla \cdot\left(\varepsilon \rho_{g} \mathbf{u}_{g} \mathbf{u}_{g}+\varepsilon \mathbf{p}\right) \\
& \quad=-\varepsilon \frac{\mu_{g}}{K} \mathbf{u}_{g}-\varepsilon \frac{C_{F}}{\sqrt{K}} \rho_{g}\left|\mathbf{u}_{g}\right| \mathbf{u}_{g}+\mathbf{v} \cdot \nabla \varepsilon \rho_{g} \mathbf{u}_{g}
\end{aligned}
$$

where the first term on the right-hand side is the Darcy term and the second term is the Forchheimer term, and $K$ and $C_{F}$ are the permeability and the Forchheimer coefficient, respectively. The third term accounts for grid motion in the numerical solution. The lefthand side of Eq. (2) is the unsteady form of the Euler equation with porosity.

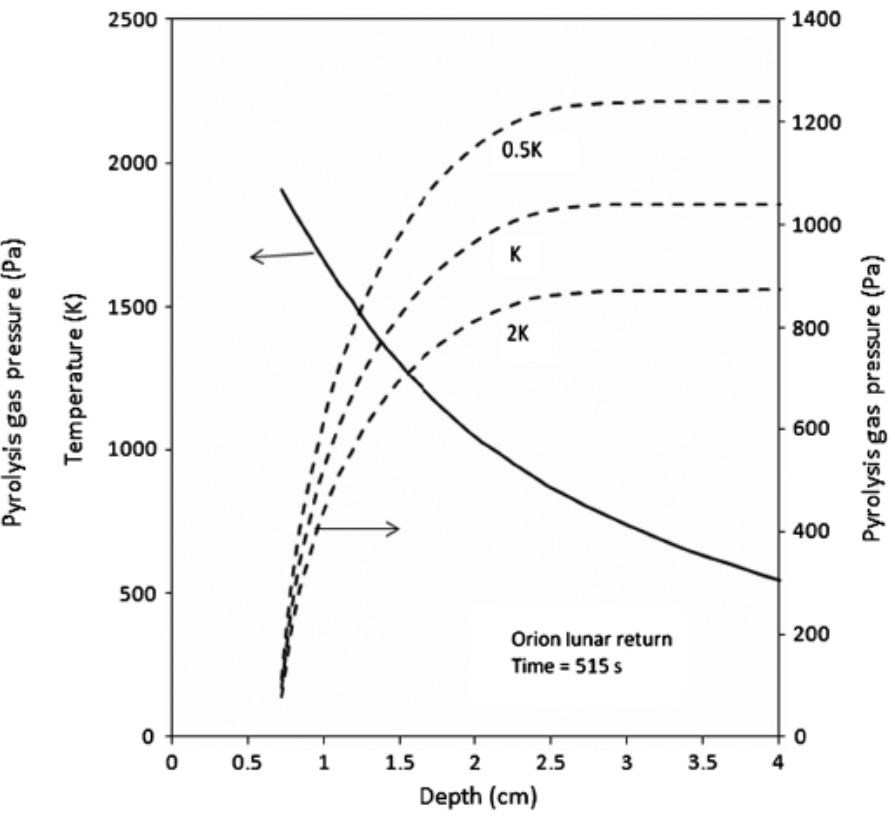

b)

Fig. 4 Temperature and pressure profiles at times equal to a) $80 \mathrm{~s}$ and b) $515 \mathrm{~s}$. 


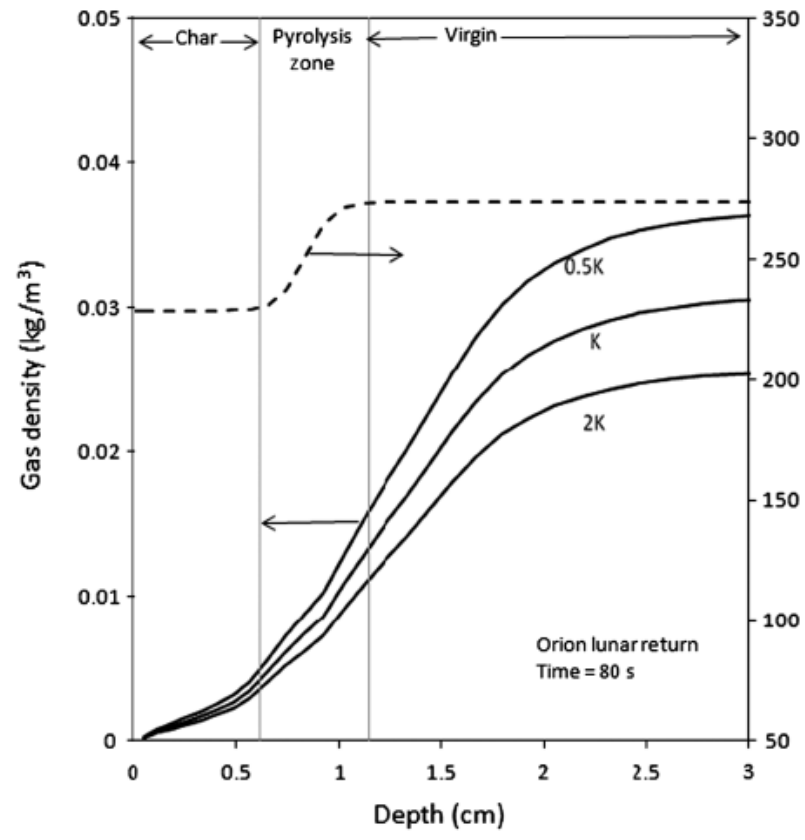

a)

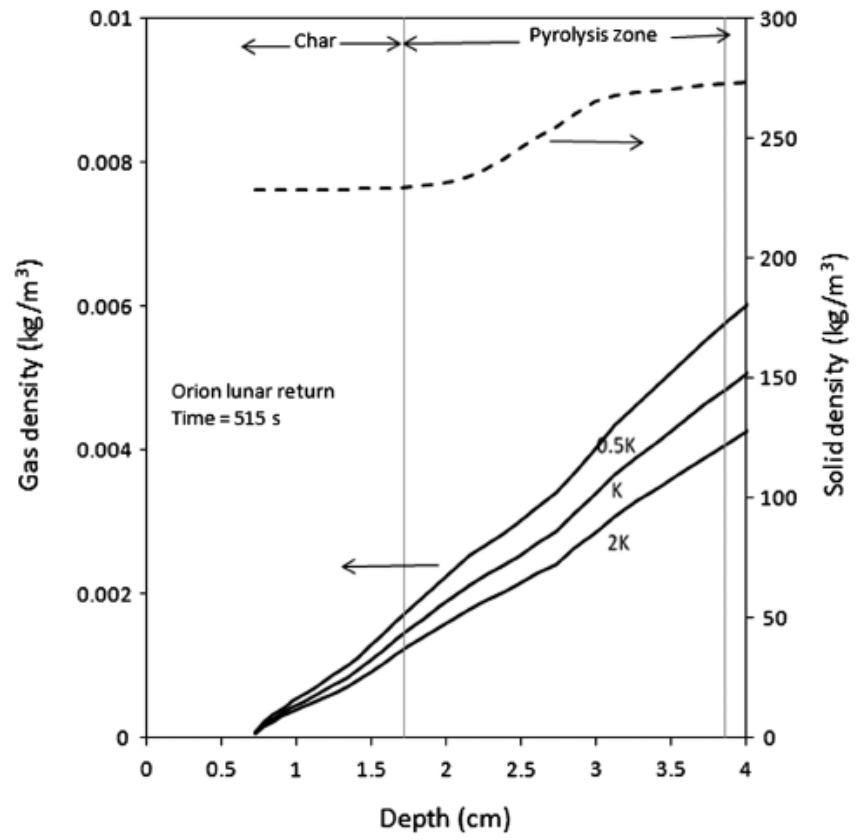

b)

Fig. 5 Gas and solid density distributions at times equal to a) $80 \mathrm{~s}$ and b) $515 \mathrm{~s}$.

Most TPS materials are nonisotropic, and therefore, the quantities $k$ and $K$ are actually tensors. However, in one dimension, we may use the scalar quantities as written in Eqs. (1) and (2). More general forms that include tensor material properties and Brinkman's term may be required for solutions in two or three dimensions.

The permeability and the Forchheimer coefficient for both virgin material and char must be defined to perform a simulation. Some models and data for permeability and the Forchheimer coefficient are available. If the pressure is not too high, the effective permeability may be expressed in the Klinkenberg form as

$$
K=K_{0}\left(1+\frac{b}{p}\right)
$$

where $K_{0}$ is the gas permeability in the limit of continuum flow, and $b$ is a permeability slip parameter that accounts for rarefied flow effects.

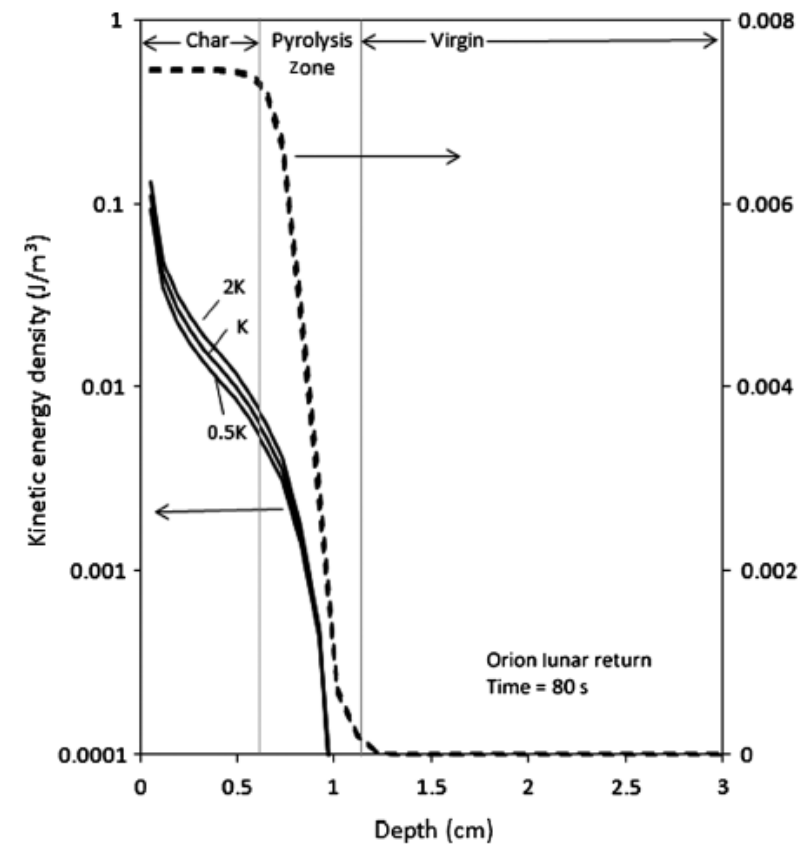

a)
Values of $K_{0}$ and $b$ for the through-the-thickness direction of PICA are found in the work of Marschall and Cox [13]. The formula for the Forchheimer coefficient used by Ward [14] and Ahn et al. [6] is adopted.

The pyrolysis gas is assumed to have $N_{s}$ components. The mass conservation for each component is

$$
\frac{\partial \varepsilon \rho_{i}}{\partial t}+\nabla \cdot\left[\varepsilon \rho_{i} \mathbf{u}_{g}+\varepsilon \rho_{g} D_{i} \nabla\left(\frac{\rho_{i}}{\rho_{g}}\right)\right]=\varepsilon \dot{R}_{i}+\dot{R}_{\mathrm{di}}+\mathbf{v} \cdot \nabla \varepsilon \rho_{i}
$$

and the global mass conservation is

$$
\frac{\partial \varepsilon \rho_{g}}{\partial t}+\nabla \cdot\left(\varepsilon \rho_{g} \mathbf{u}_{g}\right)=\sum_{i=1}^{N_{s}} \dot{R}_{\mathrm{di}}+\mathbf{v} \cdot \nabla \varepsilon \rho_{g}
$$

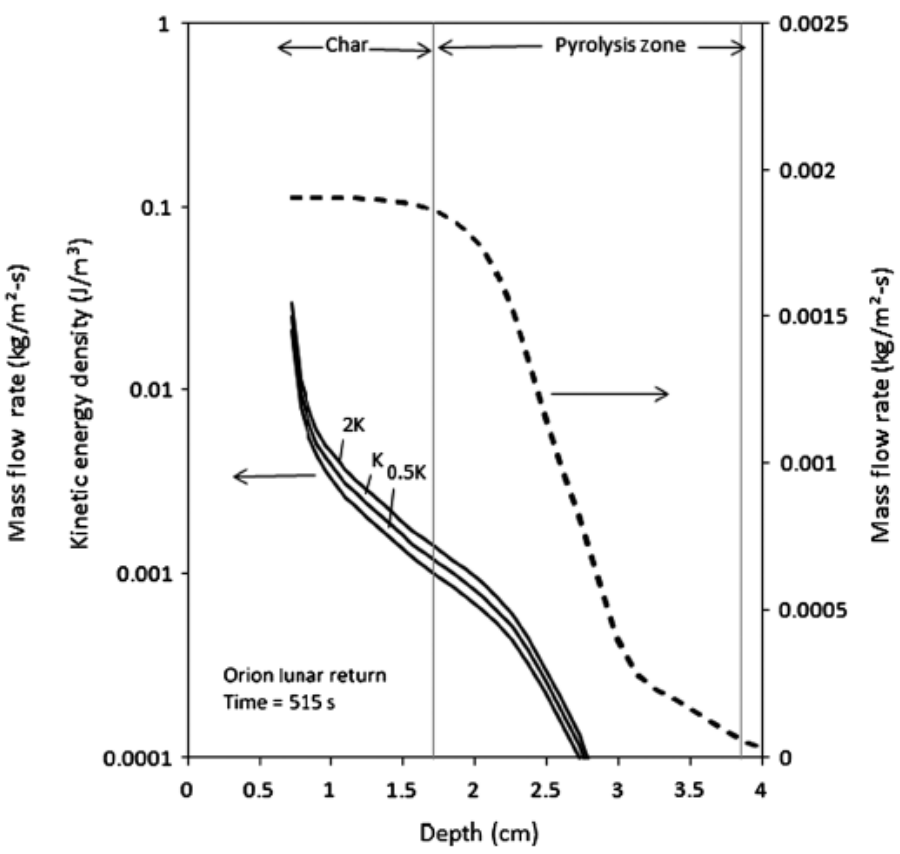

b)

Fig. 6 Kinetic energy density and mass flow rate distributions at times equal to a) $80 \mathrm{~s}$ and $515 \mathrm{~s}$. 
Here, $\dot{R}_{\mathrm{di}}$ is the mass generation rate of gas species $i$ due to resin decomposition, and $\dot{R}_{i}$ is the gas species $i$ production rate due to homogeneous gas reactions.

For pyrolyzing TPS materials, a standard three-component decomposition model is used. The instantaneous local density of the composite is given by

$$
\rho=\Gamma\left(\rho_{A}+\rho_{B}\right)+(1-\Gamma) \rho_{C}
$$

where the parameter $\Gamma$ is the volume fraction of resin and is an input quantity. The three components decompose independently following the Arrhenius type relation

$$
\frac{\partial \rho_{i}}{\partial t}=-B_{\mathrm{ai}} \exp \left(\frac{-E_{\mathrm{ai}}}{R T}\right) \rho_{\mathrm{oi}}\left(\frac{\rho_{i}-\rho_{\mathrm{ri}}}{\rho_{\mathrm{oi}}}\right)^{\Psi_{i}}+v \cdot \nabla \rho_{i}
$$

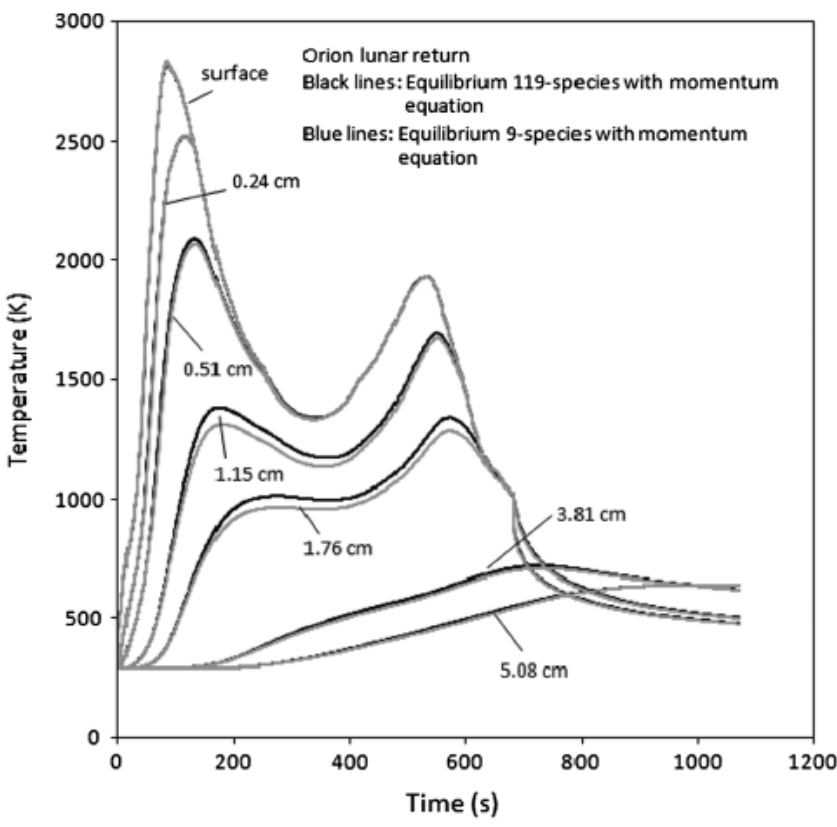

a) where $\rho_{\mathrm{ri}}$ is the residual or terminal density of component $i$, and $\rho_{\mathrm{oi}}$ is the original density of component $i . B_{a}, E_{a}$, and $\Psi$ are determined using curve fitting of thermogravimetric analysis data. The mass generation rate of each gas phase chemical species, $\dot{R}_{\mathrm{di}}$, formed during the resin decomposition can be estimated by multiplying the mass production rate computed in Eq. (7) by the mass fraction of each individual chemical species. If the resin decomposition process is under the chemical equilibrium condition, the mass fractions of chemical species can be computed using a chemical equilibrium solver, such as the aerotherm chemical equilibrium (ACE) [15] or multicomponent ablation thermochemistry (MAT) [16] codes. If the decomposition process is not in chemical equilibrium, details of the heterogeneous chemical reactions and their associated rates involved in the decomposition process are required to estimate the mass fraction of each chemical species. For the parametric studies presented in this work, the resin decomposition process is assumed to

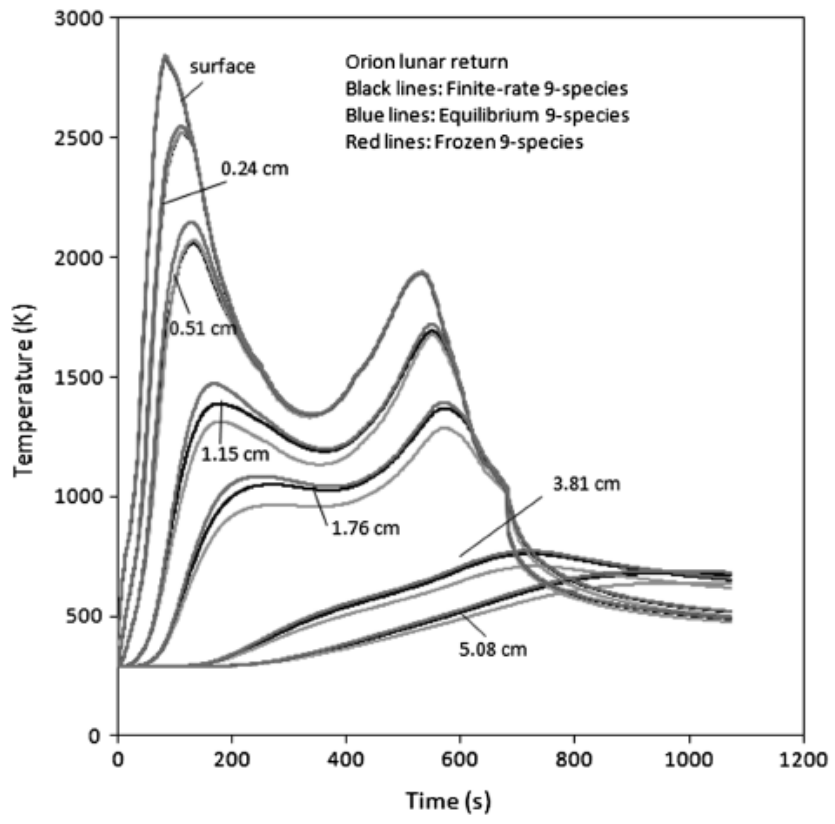

b)

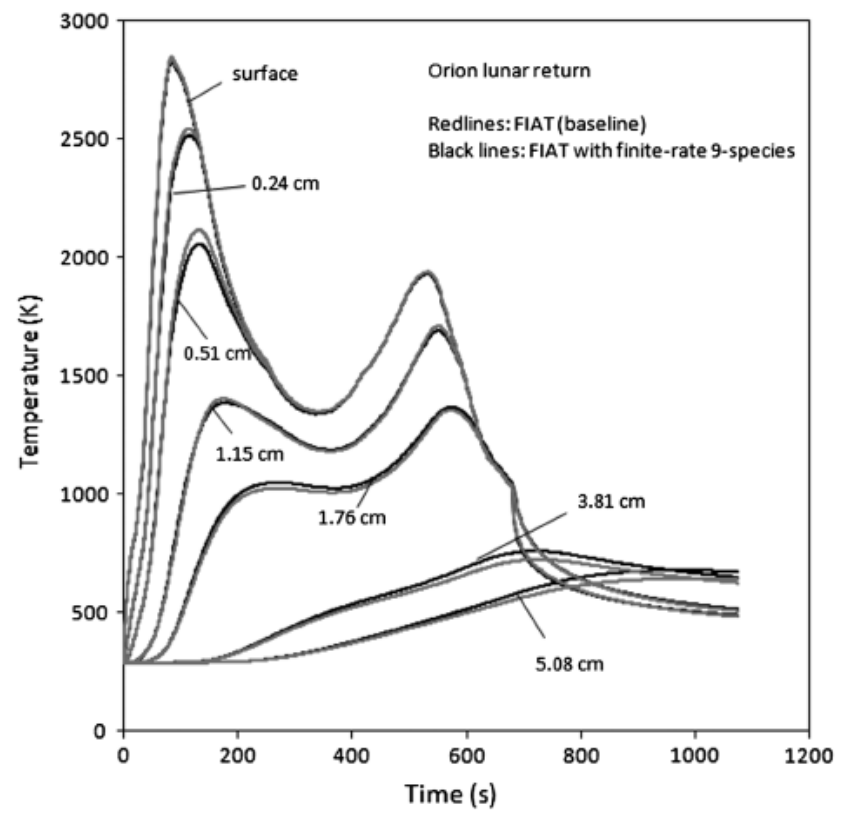

c)

Fig. 7 Surface and in-depth temperature predicted by a) 119-species and nine-species chemical equilibrium models; b) finite-rate, equilibrium, and froSurface and in-depth temperatures predicted by zen gas chemistry models; and c) baseline FIAT and by enhanced FIAT with 9-species chemistry. 


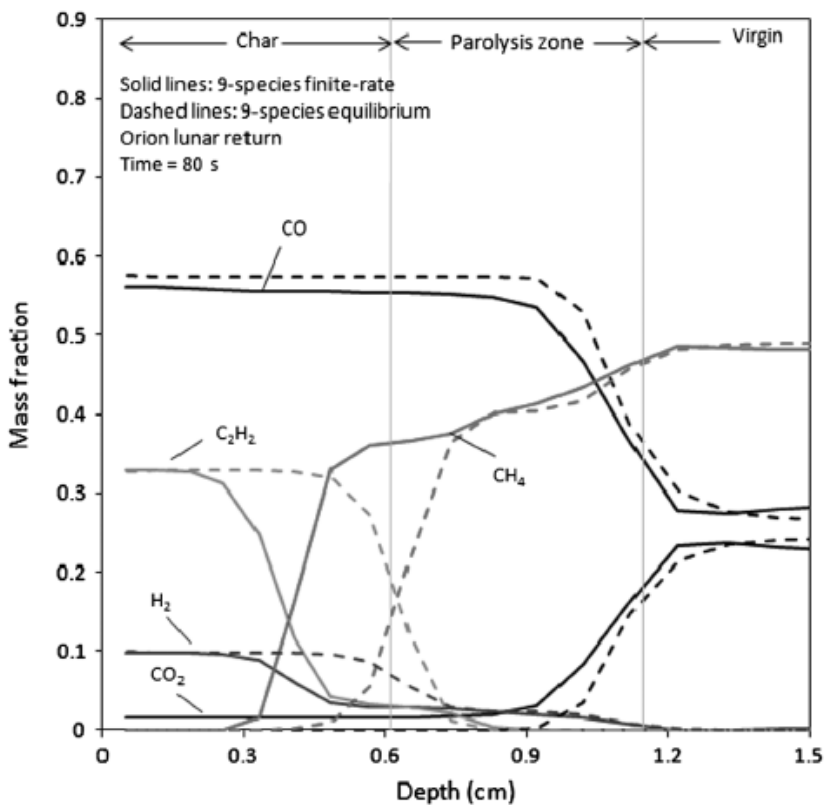

a)

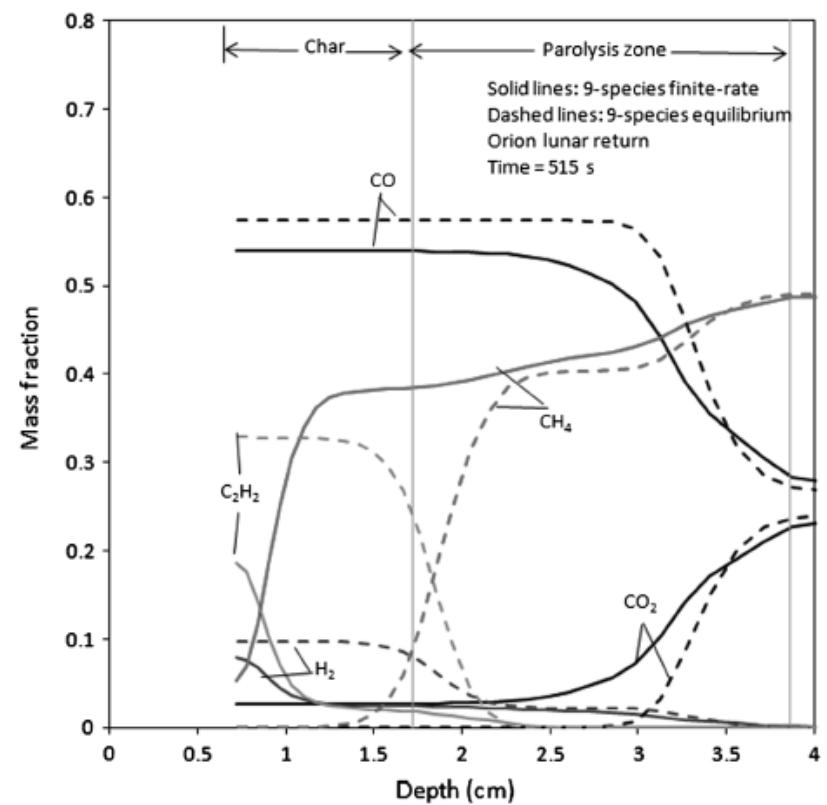

b) be under the chemical equilibrium condition. The mass fractions of chemical species formed during the resin decomposition are predetermined and then arranged in tabular form as one of the FIAT input files.

For a general homogeneous chemical reaction, the mass production rate $\dot{R}_{i}$ of gas species $i$ has the following form:

$$
\dot{R}_{i}=M_{i} \sum_{j=1}^{m}\left(p_{i j}-r_{i j}\right)\left[k_{f j} \prod_{i=1}^{N_{s}}\left(c_{i}\right)^{p_{i}^{\prime}}-k_{r j} \prod_{i=1}^{N_{s}}\left(c_{i}\right)^{r_{i}^{\prime}}\right]
$$

where $p_{i j}$ and $r_{i j}$ denote the stoichiometric coefficients of species $i$ as a product and a reactant of reaction $j ; m$ is the total number of reactions and $N_{s}$ is the total number of species; $M_{i}$ is the molecular mass; $K_{f j}$ and $K_{r j}$ are the forward and backward reaction rates; $c_{i}$ is the species concentration; and $p_{i}^{\prime}$ and $r_{i}^{\prime}$ are the orders of reaction with respect to species $i$.

A complete set of homogeneous pyrolysis gas chemistry for PICA is not possible at this time because the reactions and their rates of pyrolysis flow have not been well studied. The only pyrolysis gas chemistry found in the open literature is the work by April et al. [4]. Because no other choice was available, in this work, we adopt the gas chemistry of April et al. [4], and we assume that the pyrolysis gas formed in the PICA char layer consists of nine gas species, specifically, $\mathrm{H}_{2}, \mathrm{CH}_{4}, \mathrm{CO}, \mathrm{C}_{2} \mathrm{H}_{6}, \mathrm{C}_{2} \mathrm{H}_{4}, \mathrm{C}_{2} \mathrm{H}_{2}, \mathrm{CO}_{2}, \mathrm{H}_{2} \mathrm{O}$, and $\mathrm{C}$, which are the most abundant species for some chemical equilibrium conditions. The eight chemical reactions considered in this work and their rates are listed in Table 1. A detailed discussion of these reactions is presented in the paper by April et al. [4].

$$
k=A T^{-s} e^{(-E / R T)}
$$

The specific heat of solid is input as a function of temperature for both virgin and fully charred material. In partially pyrolyzed zones $\left(\rho_{c}<\rho<\rho_{v}\right)$, the specific heat is obtained from the mixing rule

$$
c_{p}=\tau c_{\mathrm{pv}}+(1-\tau) c_{\mathrm{pc}}
$$

where

$$
\tau=\frac{\rho_{v}}{\rho_{v}-\rho_{c}}\left(1-\frac{\rho_{c}}{\rho}\right)
$$

The weighting variable $\tau$ is the mass fraction of virgin material, in a hypothetical mixture of virgin material and char, which yields the correct local density. The thermal conductivity $k$ is weighted in a similar manner as $c_{p}$.

\section{Boundary Conditions}

Conditions at the ablating surface are determined by convective and radiative heating and by surface thermochemical interactions with boundary-layer gases. The surface energy balance equation is written in general convective transfer-coefficient form as follows:

$$
\begin{gathered}
\rho_{e} u_{e} C_{H}\left(H_{r}-h_{w}\right)+\dot{m}_{c}\left(h_{c}-h_{w}\right)+\dot{m}_{g}\left(h_{g}-h_{w}\right) \\
+\alpha_{w} q_{\mathrm{rw}}-\sigma \varepsilon_{w}\left(T_{w}^{4}-T_{\infty}^{4}\right)-q_{\mathrm{cw}}=0
\end{gathered}
$$

The first term in Eq. (12) represents the sensible convective heat flux. The sum of the second and third terms in Eq. (12) is defined as the total chemical energy at the surface. The fourth and fifth terms are the radiative heat fluxes absorbed and reradiated by the wall,

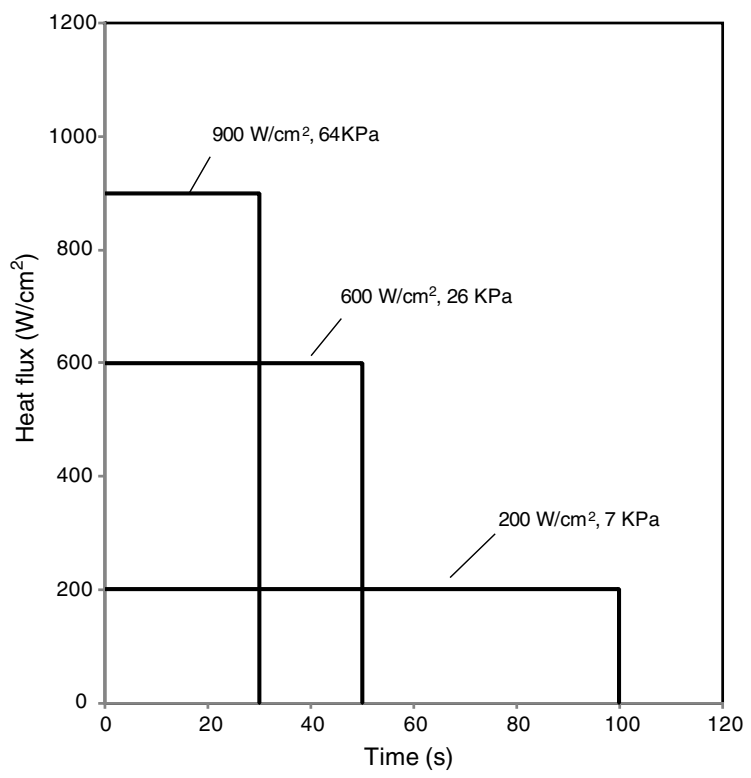

Fig. 9 Three arcjet test conditions for group II. 
respectively, and the last term, $q_{\mathrm{cw}}$, represents the rate of heat conduction into the TPS. If the surface is at the chemical equilibrium condition, ACE and MAT codes can be used to generate tables of normalized mass blowing rate, $B_{c}^{\prime}\left(=\frac{\dot{m}_{c}}{\rho_{e} u_{e} C_{M}}\right)$. For a chemical nonequilibrium surface, the char recession rate $\dot{m}_{c}$ can be computed through coupling FIAT and a computational fluid dynamics code with finite-rate surface chemistry capability, such as data-parallel line relaxation [17]. The enhanced version of FIAT code can read either the $B^{\prime}$ tables or the char recession rates, $\dot{m}_{c}$.

A blowing correction accounts for the reduction in transfer coefficients due to the transpiration of gases from pyrolysis and surface ablation into the boundary layer. The blowing rate correction equation for convective heat transfer is

$$
\frac{C_{H}}{C_{H 1}}=\frac{\ln \left(1+2 \lambda B^{\prime}\right)}{2 \lambda B^{\prime}}
$$

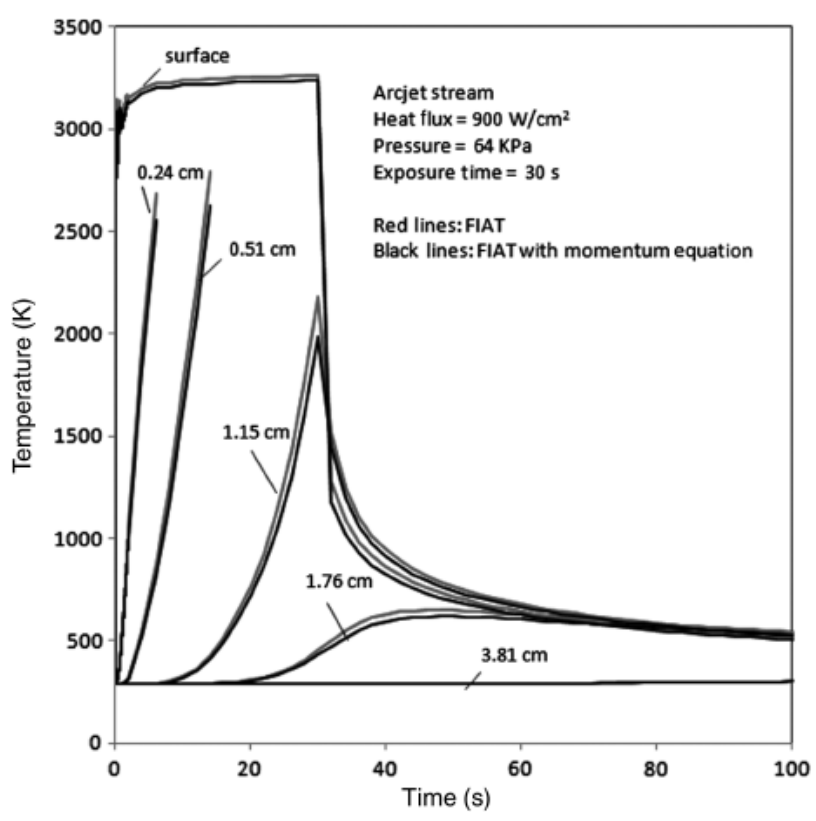

a)

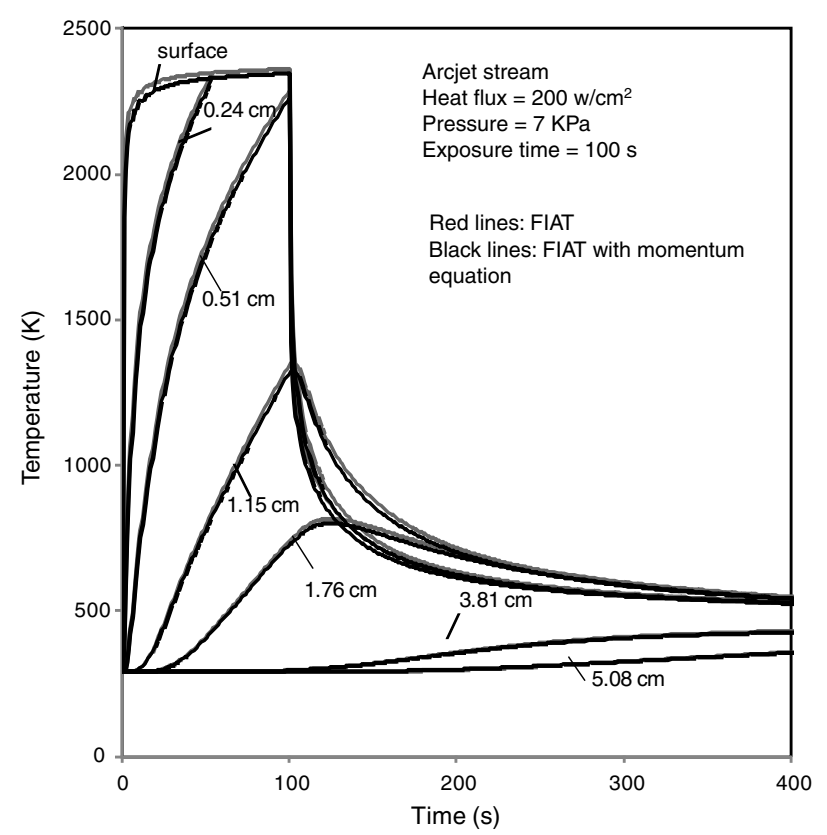

c)

Fig. 10 Surface and in-depth temperatures predicted by baseline FIAT and by enhanced FIAT with chemical equilibrium chemistry for a) heat flux of $900 \mathrm{~W} / \mathrm{cm}^{2}$ and pressure of $64 \mathrm{kPa}$, b) heat flux of $600 \mathrm{~W} / \mathrm{cm}^{2}$ and pressure of $26 \mathrm{kPa}$, and c) heat flux of $200 \mathrm{~W} / \mathrm{cm}^{2}$ and pressure of $7 \mathrm{kPa}$. where $\lambda$ is the blowing reduction parameter, $C_{H}$ is the heat transfer coefficient for the ablating surface, and $C_{H 1}$ is the heat transfer coefficient for the nonablating surface. With $\lambda=0.50$, Eq. (13) reduces to the classical blowing correction for laminar flow [18].

\section{Test Cases}

The computations presented in this section focus on the in-depth thermal response of PICA heat-shield material. The first group of simulations is based on a lunar return trajectory for Orion, and the second group uses a representative variety of stream conditions for Crew Exploration Vehicle (CEV) TPS ADP arcjet testing conducted at NASA Ames Research Center. The effects of gas momentum transfer and pyrolysis gas homogeneous reactions on PICA in-depth thermal response are examined. In each group, we first solve the Darcy-Forchheimer momentum equation under the assumption of

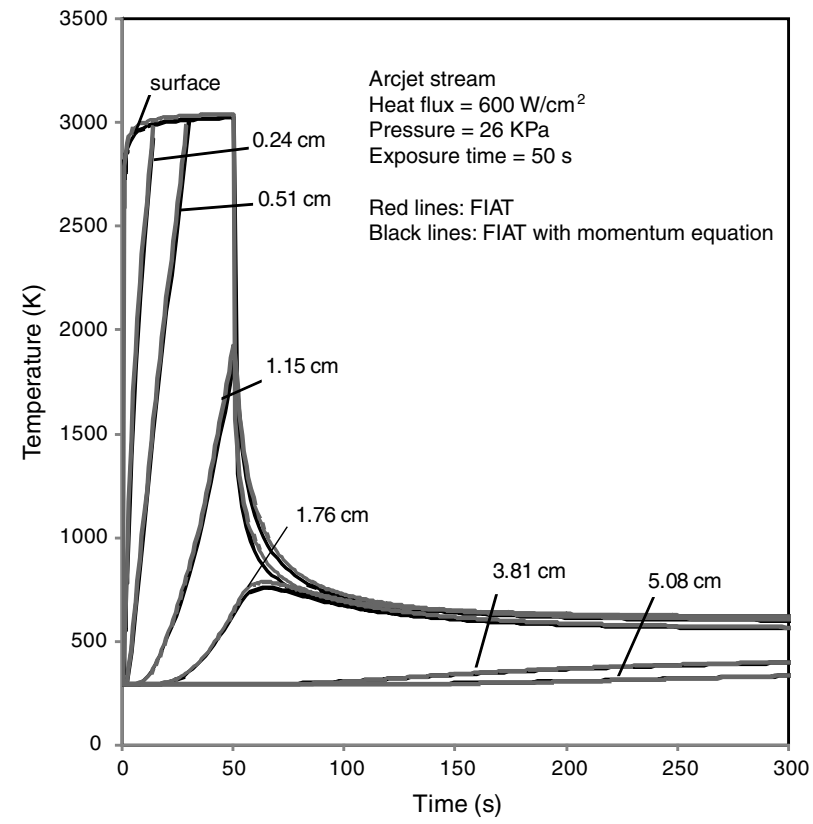

b)

\section{Arcjet stream}

Pressure $=7 \mathrm{KPa}$

Exposure time $=100$

Red lines: FIAT

Black lines: FIAT with momentum

quation

Time $(s)$ 
chemical equilibrium to understand how the inclusion of gas momentum transfer and gas kinetic energy affects the in-depth temperature prediction. Then, the gas momentum equation is solved with finite-rate homogeneous reactions, developed by April et al. [4] for pyrolysis gas flow, to study how the gas phase chemistry influences the PICA material thermal response. For each group, the predictions of PICA material thermal response using nine-species finite-rate gas chemistry, equilibrium gas chemistry, and frozen gas chemistry are presented and compared with those using the baseline FIAT/PICA model developed for CEV TPS ADP.

\section{A. Group I}

The aerothermal environment for the first group is shown in Fig. 1. This flight environment is a dual convective heat pulse based on a proposed lunar return trajectory for Orion. The first peak convective heat flux is $245 \mathrm{~W} / \mathrm{cm}^{2}$ at $105 \mathrm{~s}$, and the second peak is $85 \mathrm{~W} / \mathrm{cm}^{2}$ at $523 \mathrm{~s}$. The radiative heat flux is a single pulse with a maximum of $204 \mathrm{~W} / \mathrm{cm}^{2}$ at $80 \mathrm{~s}$.

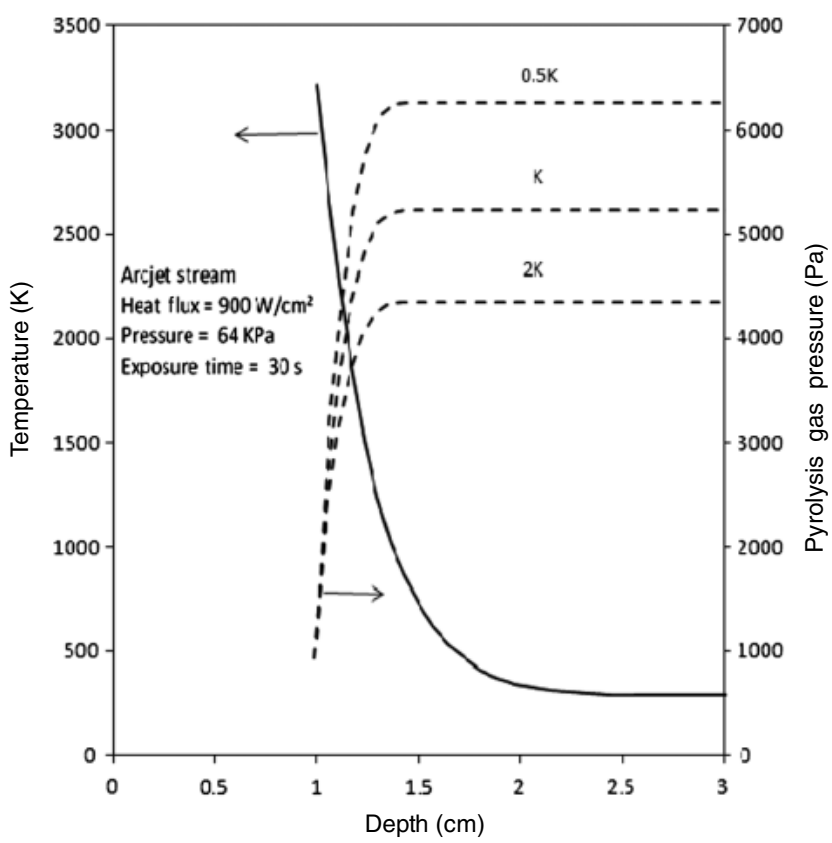

a)

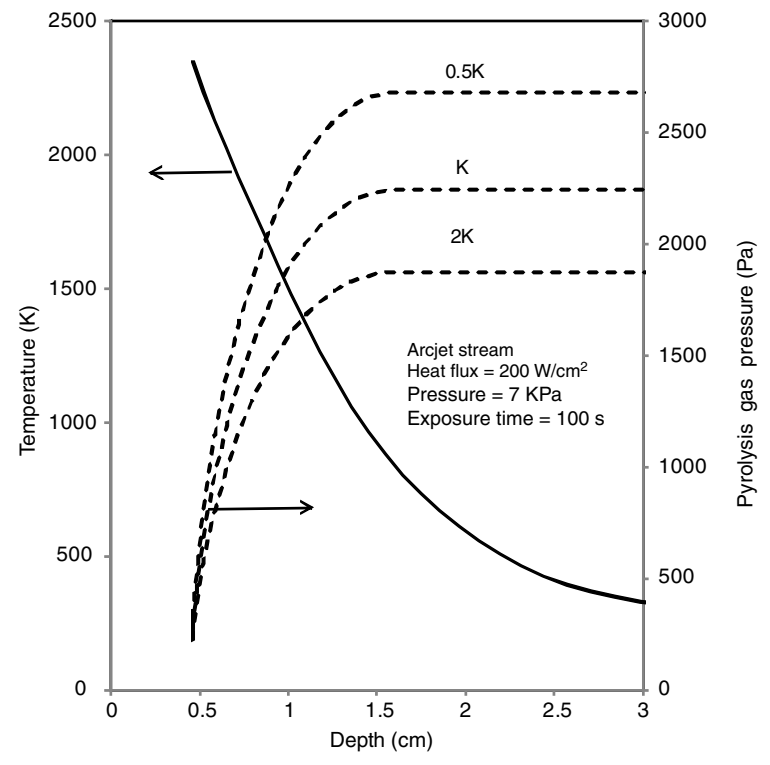

c)

Fig. 11 Temperature and gas pressure profiles for a) heat flux of $900 \mathrm{~W} / \mathrm{cm}^{2}$ and pressure of $64 \mathrm{kPa}$ at time equal to $\left.30 \mathrm{~s}, \mathrm{~b}\right) \mathrm{heat}$ flux of $600 \mathrm{~W} / \mathrm{cm}^{2}$ and pressure of $26 \mathrm{kPa}$ at time equal to $50 \mathrm{~s}$, and c) heat flux of $200 \mathrm{~W} / \mathrm{cm}^{2}$ and pressure of $7 \mathrm{kPa}$ at time equal to $100 \mathrm{~s}$.
The gray lines shown in Fig. 2 are the PICA in-depth temperature histories at various depths (surface, $0.24,0.51,1.15,1.76,3.81$, and $5.08 \mathrm{~cm}$ ) predicted by the regular version of FIAT using the baseline thermal response model, PICAv3.3, developed for CEV TPS ADP. The black lines are predictions of the enhanced version of FIAT, which solves the Darcy-Forchheimer momentum equation and the global mass conservation equation with, in this case, the assumption of chemical equilibrium for the pyrolysis gas flow. Both predictions are performed using a baseline 119-species pyrolysis gas model. In general, the enhanced version predicts slightly lower in-depth temperature than the regular version for locations inside the char and pyrolysis zones. At depths of 3.81 and $5.08 \mathrm{~cm}$, at which the temperature is not sufficiently high for pyrolysis to be significant, the difference between these two predictions is very small. Consideration of the gas momentum equation does not appear to have significant impact on the thermal response prediction. The difference in energy of pyrolysis gas in the total energy balance equation [Eq. (1)].

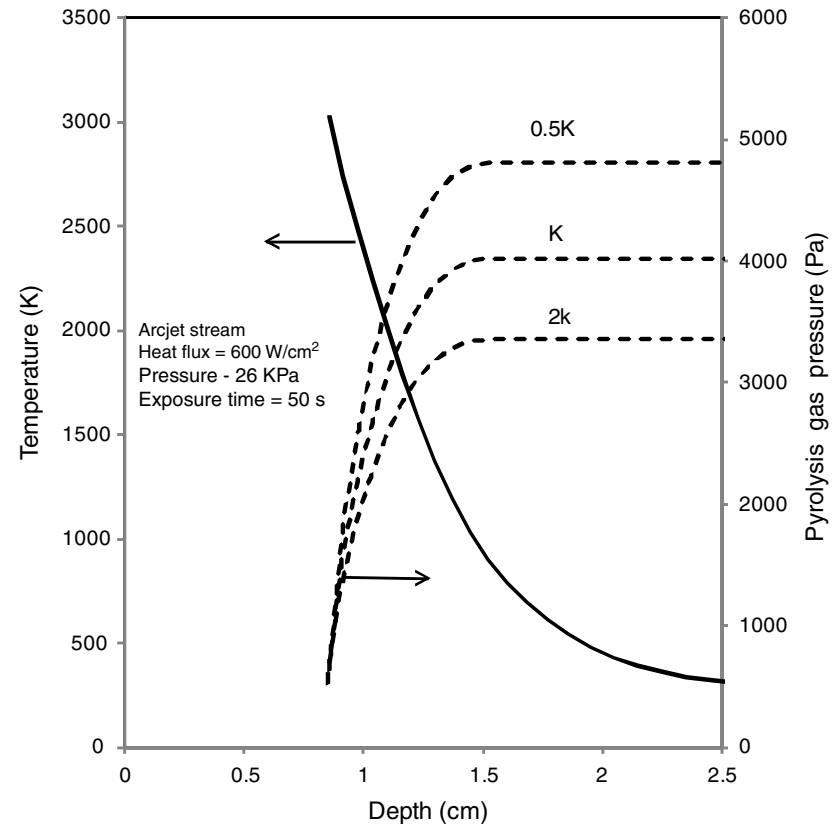

b) temperature prediction is mainly driven by the introduction of kinetic 
The gas kinetic energy is not considered in the energy balance terms of the regular version of FIAT. One can conclude that the kinetic energy of pyrolysis gas is a relatively small component in the global energy balance of PICA material, and thus, the difference in predicted temperatures between two simulations is small. Thus, for flow environments studied in this case, ignoring the kinetic energy of pyrolysis gas should not have a significant impact on the accuracy of PICA material thermal response predictions. However, in a material thermal response model with finite-rate gas chemistry, an accurate prediction of the gas flow rate is required for the computation of chemical species concentrations.

The pyrolysis gas mass injection rate vs time is presented in Fig. 3. The prediction from the regular version of FIAT (in gray) is just slightly higher than that from the enhanced version (in black). Instead

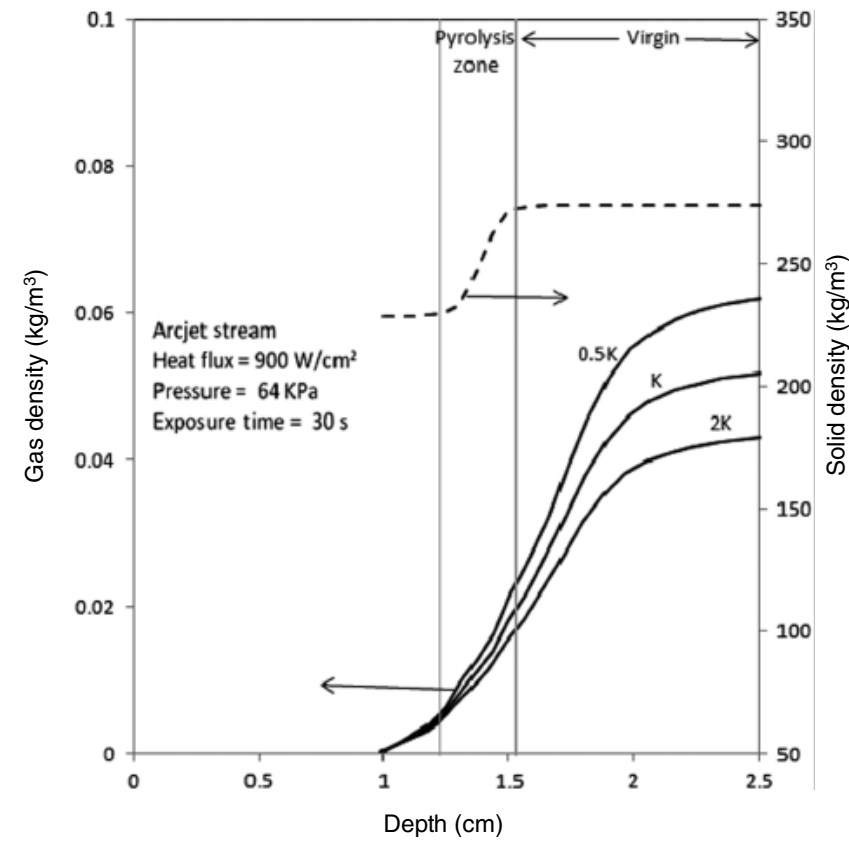

a) of solving the gas momentum conservation equation and each individual gas species mass conservation equation, the regular version of FIAT code assumes that all pyrolysis gas flowing outward with neither resistance nor accumulation, and thus, the gas flow rate, can be obtained by simply solving the global gas mass conservation equation. Based on the results of the current analysis, this assumption is proved to be reasonable for the flight conditions considered here.

To examine the effect of variation of permeability on PICA indepth thermal response, computations with various values of permeability are performed. The results presented are for the permeabilities equal to baseline value $(K)$, twice baseline $(2 K)$, and half of baseline $(0.5 K)$. Figures $4 \mathrm{a}$ and $4 \mathrm{~b}$ show the in-depth temperature and gas pressure profiles at $80 \mathrm{~s}$, the first peak of surface temperature, and at $515 \mathrm{~s}$, the second peak of surface temperature, respectively. The

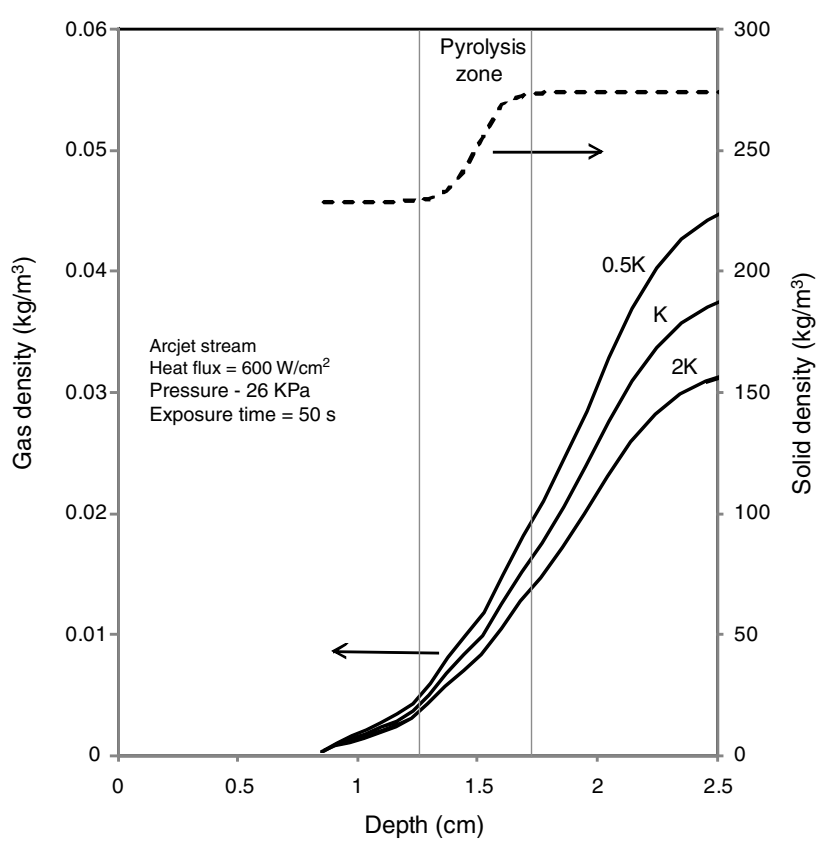

b)

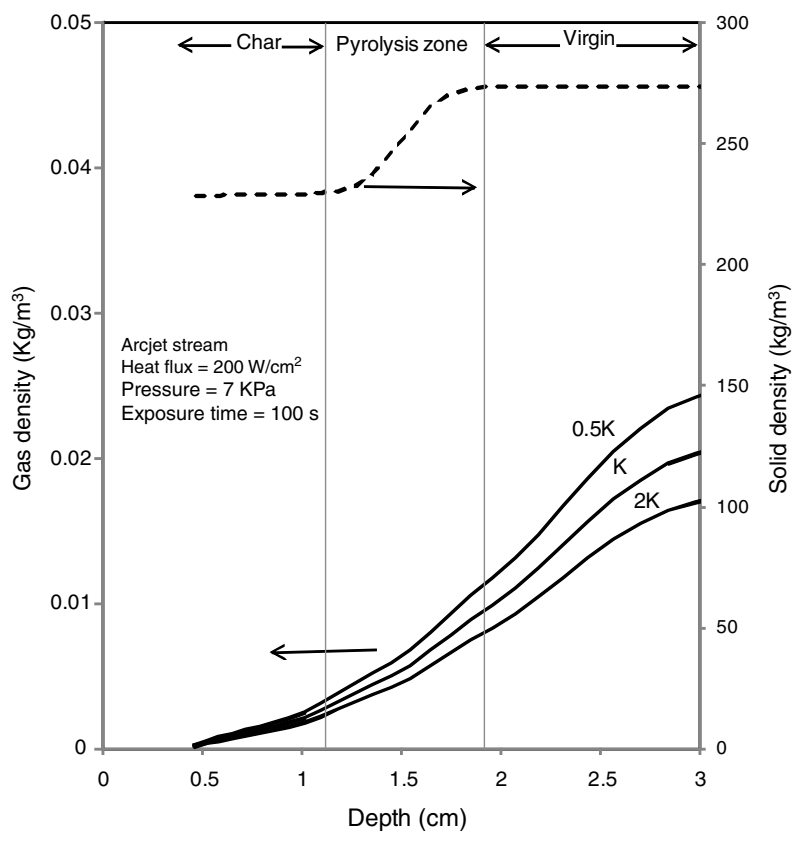

c)

Fig. 12 Gas density and solid density profiles for a) heat flux of $900 \mathrm{~W} / \mathrm{cm}^{2}$ and pressure of $64 \mathrm{kPa}$ at time equal to $30 \mathrm{~s}, \mathrm{~b}$ ) heat flux of $600 \mathrm{~W} / \mathrm{cm}^{2}$ and pressure of $26 \mathrm{kPa}$ at time equal to $50 \mathrm{~s}$, and c) heat flux of $200 \mathrm{~W} / \mathrm{cm}^{2}$ and pressure of $7 \mathrm{kPa}$ at time equal to $100 \mathrm{~s}$. 
temperature distributions are almost unaffected by the variation of permeability. The maximum temperature difference due to the variation of permeability is $20 \mathrm{~K}$, which is too small to be seen in this plot. Thus, only the temperature distribution for baseline permeability is shown in this chart. The increase in pyrolysis gas pressure is about 15 to $20 \%$, as the permeability is reduced by $50 \%$, and conversely, the pyrolysis gas pressure decreases if the permeability increases. The predicted pyrolysis gas density and solid density are plotted in Figs. 5a and 5b for the same time steps ( 80 and $515 \mathrm{~s}$ ). The effect of variation of permeability on gas density is similar to that on gas pressure. In Figs. 6a and 6b, the gas kinetic energy density and pyrolysis mass flow rate at time equal to 80 and $515 \mathrm{~s}$ are presented. As expected, flow speed and kinetic energy increase as the value of permeability increases. The total pyrolysis mass flow rate, which mostly depends on the resin decomposition rate, is not sensitive to the variation of permeability.

The selection of chemical species is limited by the availability of an applicable finite-rate gas chemistry model. To better estimate the uncertainty associated with using a simple nine-species gas chemistry for predicting PICA material in-depth thermal response, a corresponding nine-species chemical equilibrium gas chemistry model was used. Both the equilibrium and the finite-rate models contain exactly the same nine chemical species. In Fig. 7a, the comparison of FIAT predictions between the baseline 119-species equilibrium chemistry model (in black), which is used in the regular version of the FIAT/PICA model, and the simple nine-species

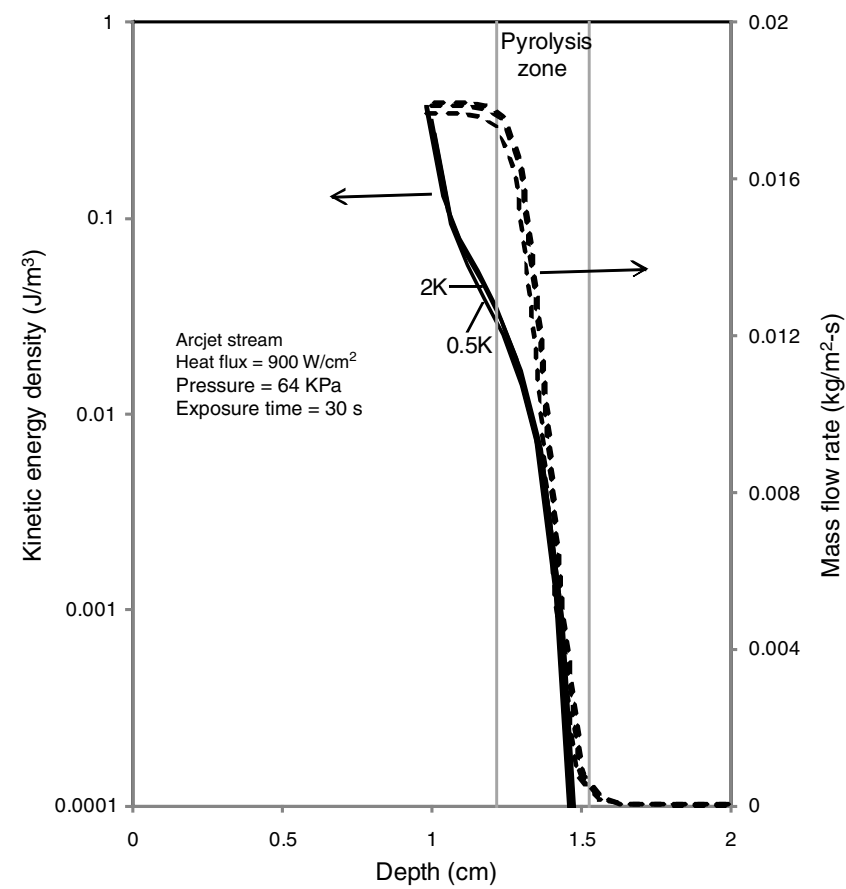

a)

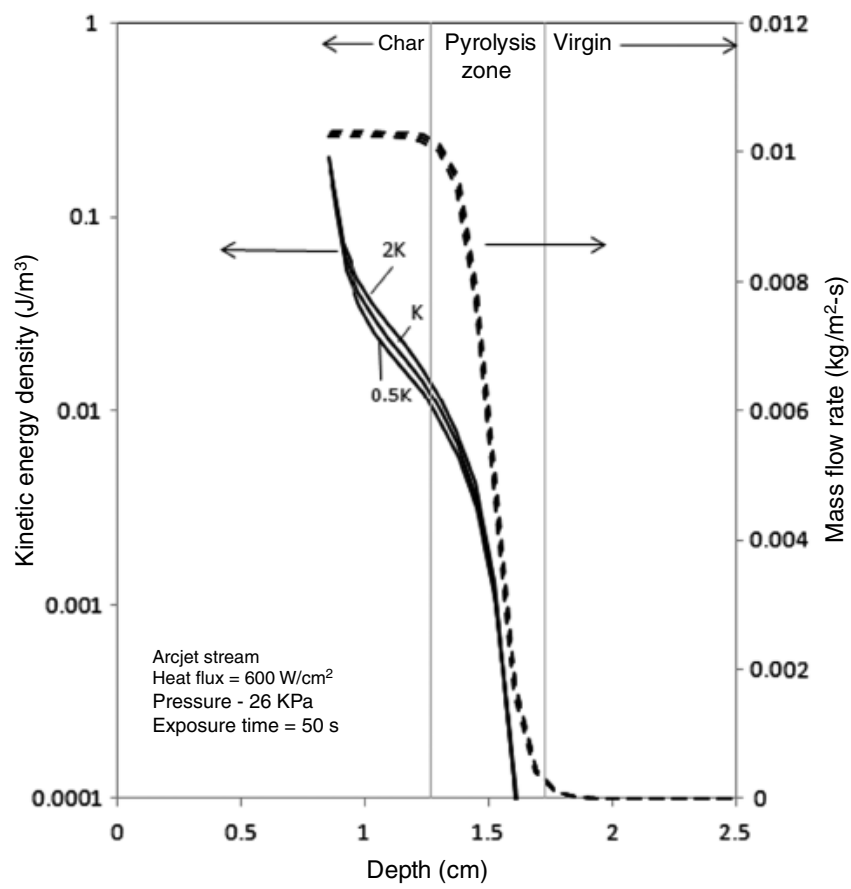

b)

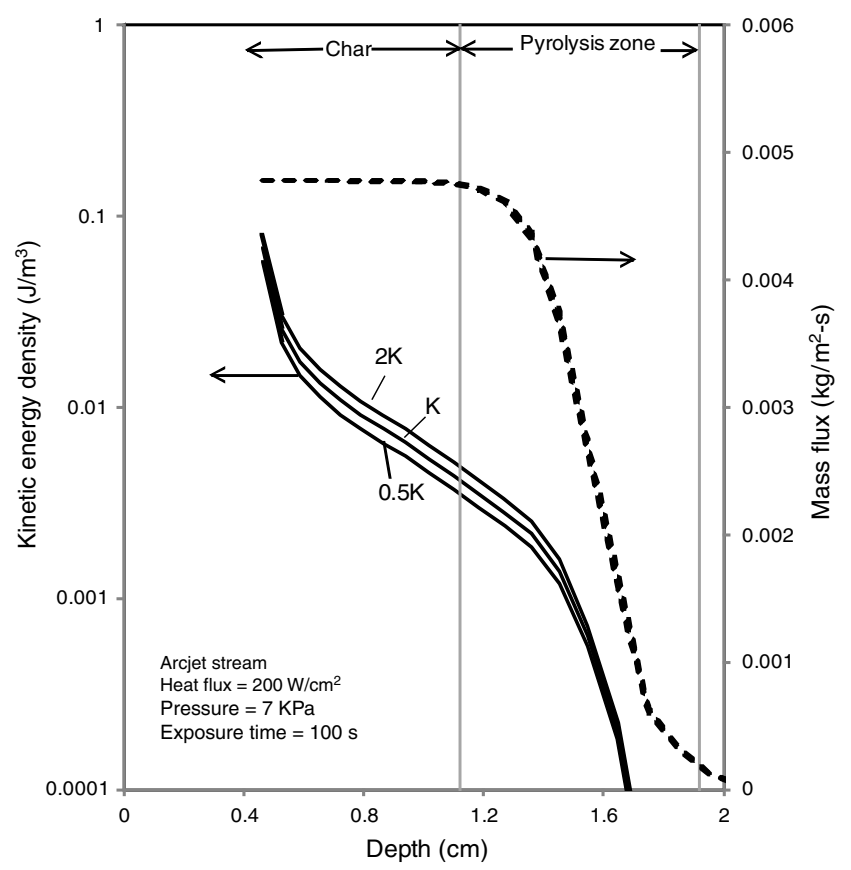

c)

Fig. 13 Kinetic energy density and mass flow rate profiles for a) heat flux of $900 \mathrm{~W} / \mathrm{cm}^{2}$ and pressure of $64 \mathrm{kPa}$ at time equal to $30 \mathrm{~s}$, b) heat flux of $600 \mathrm{~W} / \mathrm{cm}^{2}$ and pressure of $26 \mathrm{kPa}$ at time equal to $50 \mathrm{~s}$, and c) heat flux of $200 \mathrm{~W} / \mathrm{cm}^{2}$ and pressure of $7 \mathrm{kPa}$ at time equal to $100 \mathrm{~s}$. 
equilibrium chemistry model (in gray) is presented. The difference in predicted in-depth temperature profiles between the nine-species and 119-species chemical equilibrium models is fairly small, except at depths of 1.15 and $1.76 \mathrm{~cm}$, where the nine-species predictions are lower than those of 119-species predictions. This discrepancy is mainly due to differences in the gas enthalpy inside the pyrolysis zone. The difference in predicted in-depth temperature between these two equilibrium chemistry models is considered to be acceptable for the purpose of this parametric study. Since there is no other finite-rate gas chemistry model available, we have to accept the errors that may be generated as the result of using a simple nine-species model for the parametric studies performed in this section. The number of gas phase chemical species should be increased in a future study, when a more robust finite-rate homogeneous reaction model becomes available.

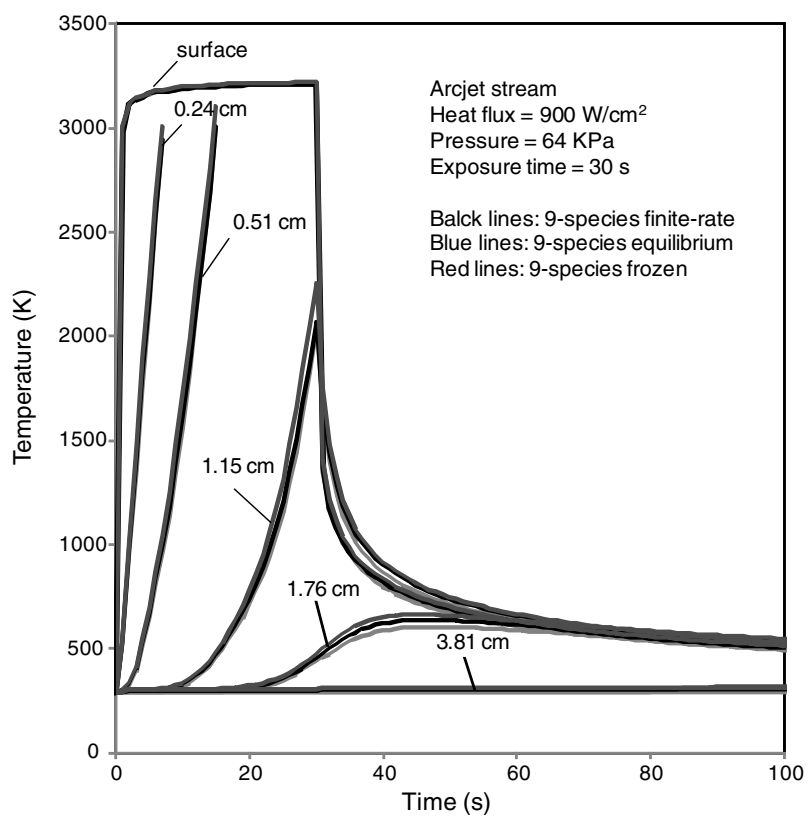

a)

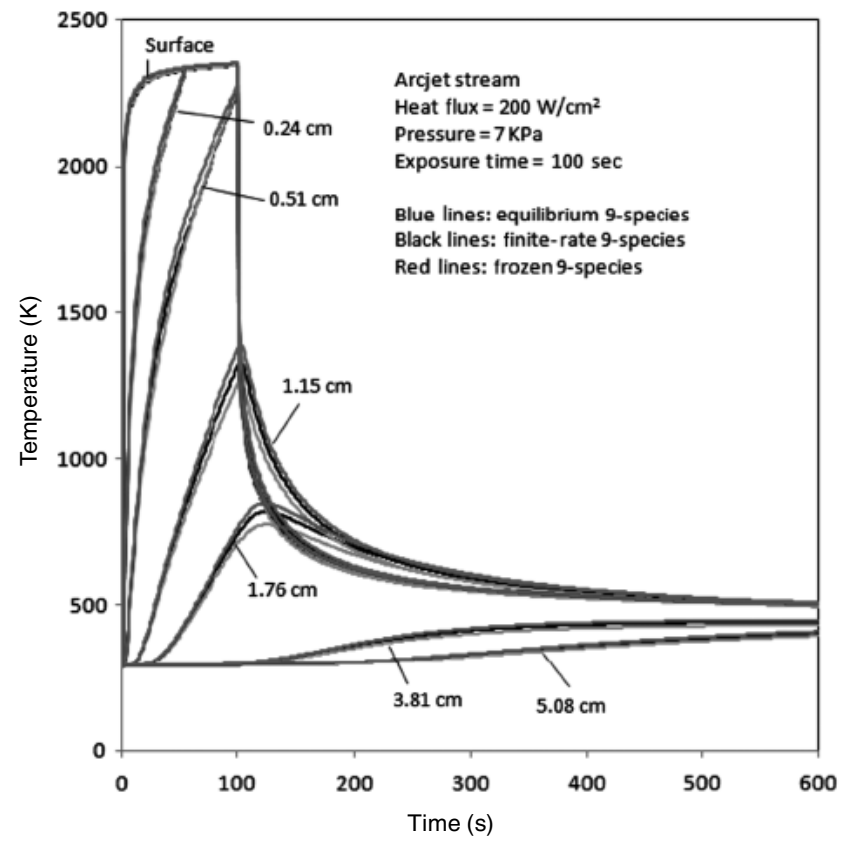

c)

Fig. 14 Surface and in-depth temperatures predicted by finite-rate, equilibrium, and frozen gas chemistry models for a) heat flux of $900 \mathrm{~W} / \mathrm{cm}^{2}$ and pressure of $64 \mathrm{kPa}$, b) heat flux of $600 \mathrm{~W} / \mathrm{cm}^{2}$ and pressure of $26 \mathrm{kPa}$, and c) heat flux of $200 \mathrm{~W} / \mathrm{cm}^{2}$ and pressure of $7 \mathrm{kPa}$.

Figure $7 \mathrm{~b}$ presents the in-depth temperature profiles for the finiterate (black lines), frozen (dark gray lines), and equilibrium (light gray lines) models with nine chemical species. The frozen chemistry solutions are obtained by turning off all the reactions in the finite-rate model. The greatest difference among these three models occurs at a depth of $1.76 \mathrm{~cm}$. Generally speaking, the frozen chemistry has the highest temperature predictions, and the equilibrium chemistry has the lowest. This discrepancy is certainly due to the difference in the gas phase chemical reaction rates in each model.

A comparison of temperature profiles between the nine-species finite-rate chemistry model (black lines) and the regular FIAT model (gray lines) is presented in Fig. 7c. The overall difference between these two predictions is not insignificant. At depths of 0.24 and $0.51 \mathrm{~cm}$, where PICA is fully charred most of the time, the regular FIAT model predicts a slightly lower temperature as compared with

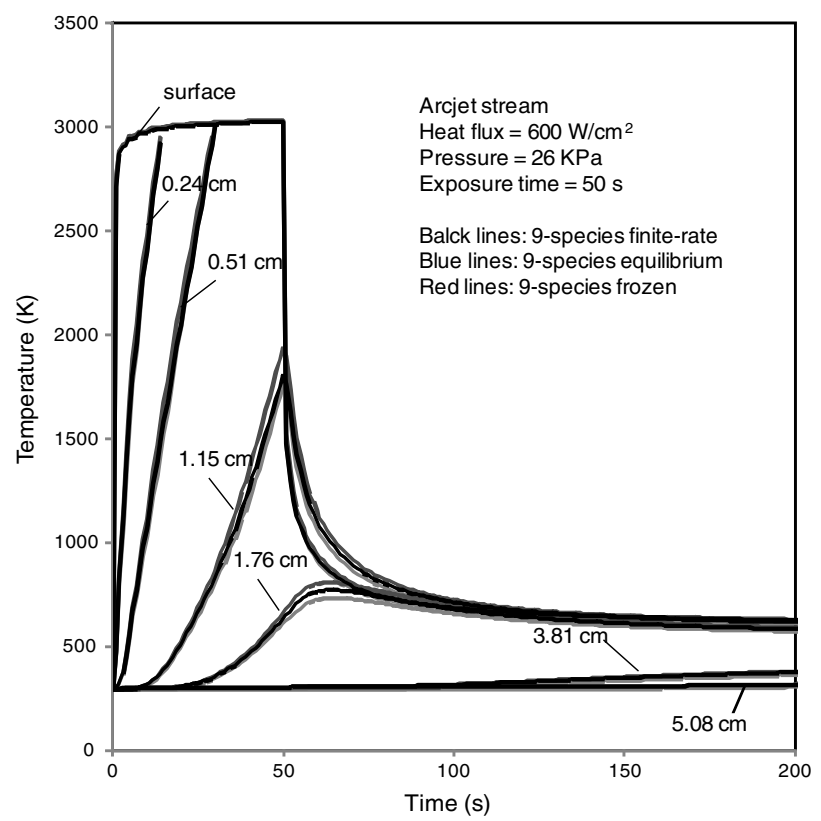

b) 
the nine-species finite-rate FIAT, due to the difference in accounting for gas kinetic energy. At deeper locations, including 1.76, 3.81, and $5.08 \mathrm{~cm}$, the kinetic energy term is less important. The gas enthalpy is the main difference between these two models, and thus, the temperature predictions of the nine-species finite-rate model are slightly higher than those of the regular version.

Figures $8 \mathrm{a}$ and $8 \mathrm{~b}$ compare the mass concentrations for $\mathrm{CO}_{2}$, $\mathrm{C}_{2} \mathrm{H}_{2}, \mathrm{CH}_{4}, \mathrm{H}_{2}$, and $\mathrm{CO}$ predicted by the finite-rate (solid lines) and equilibrium (dashed lines) gas chemistry models at 80 and $515 \mathrm{~s}$, respectively. The mass fractions for the other four species are not presented because of their relatively low concentrations. The pyrolysis gas flow is first produced inside the pyrolysis zone, expands into the char zone, reaches the front face, and then mixes with the flow surrounding the TPS system. For a chemical equilibrium model, the local chemical species concentrations depend on local temperature and pressure. However, for a finite-rate model, the individual chemical species concentration is driven by the production rate of each individual species, which is a time-dependent process. The history of local species concentrations, temperature, pressure, and flow speed all affect the extent to which the finite-rate chemistry model approaches a chemical equilibrium condition. At time equal to $80 \mathrm{~s}$, the finite-rate model prediction gradually approaches chemical equilibrium as the pyrolysis gas flow moves near the front surface. Nonetheless, in this same region, at time equal to $515 \mathrm{~s}$, the species concentrations predicted using the finite-rate model still have not reached those predicted using the chemical equilibrium model, because of relatively low gas density and pressure. We again note that this finite-rate model excludes heterogeneous reactions that may be important and that could increase the rate at which pyrolysis gas chemistry approaches equilibrium conditions.

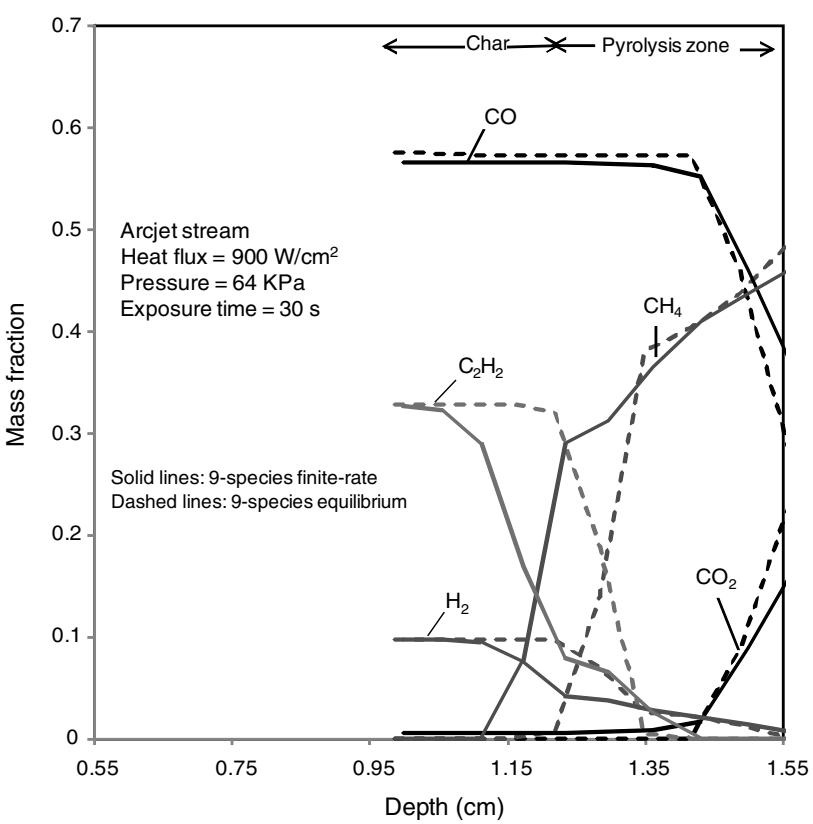

a)

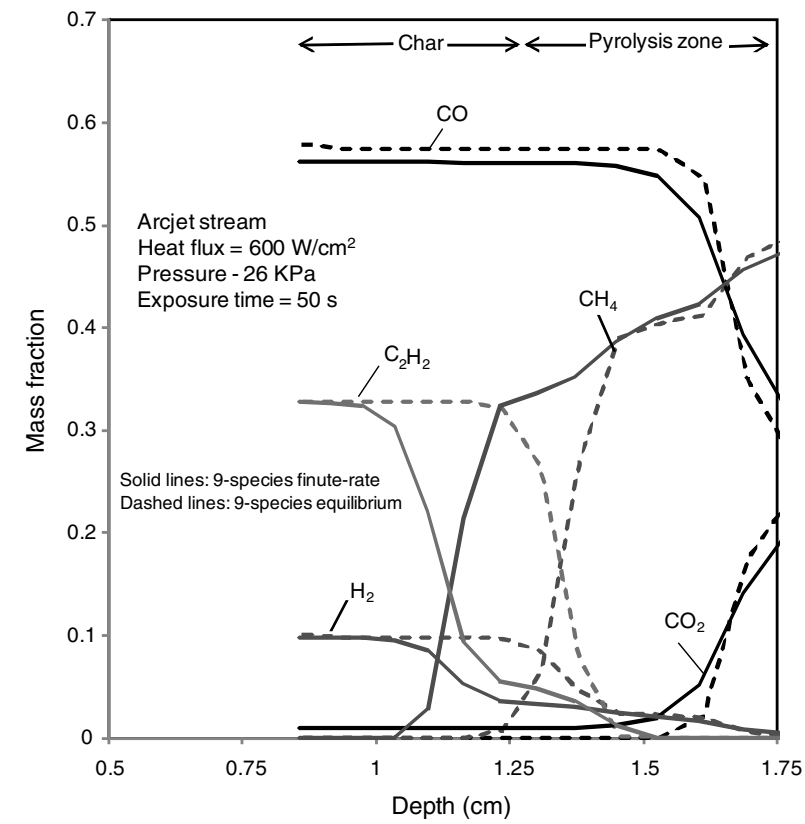

b)

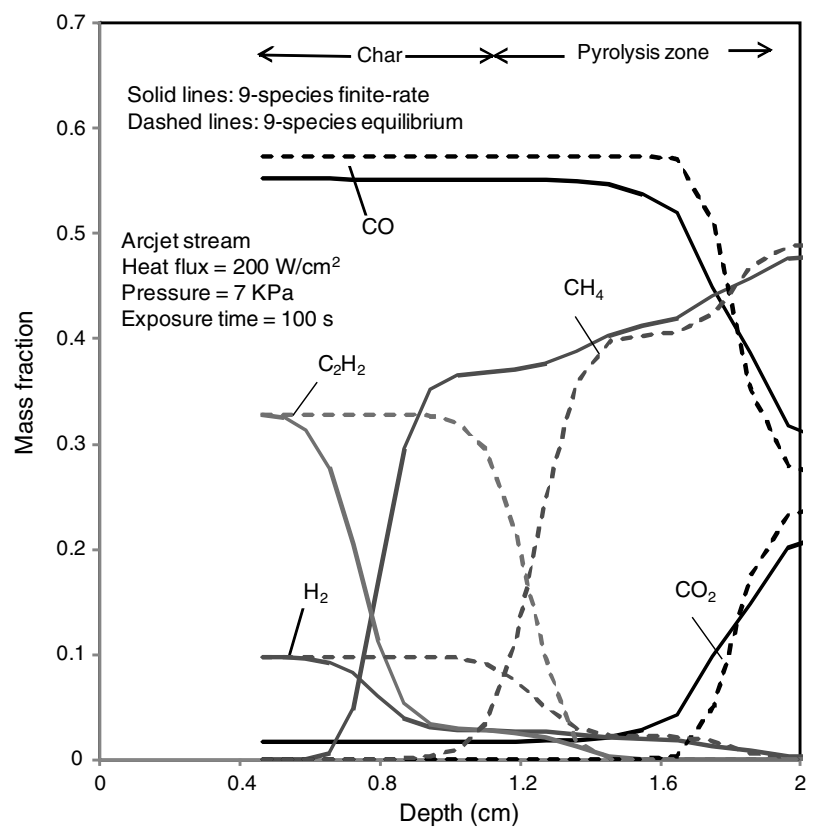

c)

Fig. 15 Mass fraction profiles predicted by finite-rate and chemical equilibrium chemistry models for a) heat flux of $900 \mathrm{~W} / \mathrm{cm}^{2}$ and pressure of $64 \mathrm{kPa}$ at time equal to $30 \mathrm{~s}$, b) heat flux of $600 \mathrm{~W} / \mathrm{cm}^{2}$ and pressure of $26 \mathrm{kPa}$ at time equal to $50 \mathrm{~s}$, and c) heat flux of $200 \mathrm{~W} / \mathrm{cm}^{2}$ and pressure of $7 \mathrm{kPa}$ at time equal to $100 \mathrm{~s}$. 


\section{B. Group II}

Figure 9 shows three representative arcjet heating environments for the second group of FIAT simulations. The first case has a surface heat flux of $900 \mathrm{~W} / \mathrm{cm}^{2}$, pressure of $64 \mathrm{kPa}$, and exposure duration of $30 \mathrm{~s}$. The second case has a surface heat flux of $600 \mathrm{~W} / \mathrm{cm}^{2}$, pressure of $26 \mathrm{kPa}$, and exposure duration of $50 \mathrm{~s}$. The third case has a surface heat flux of $200 \mathrm{~W} / \mathrm{cm}^{2}$, pressure of $7 \mathrm{kPa}$, and exposure duration of $100 \mathrm{~s}$. The computations performed in this group are similar to those in group I.

Figures $10 \mathrm{a}$ to $10 \mathrm{c}$ present temperature histories at various depths (surface, $0.24,0.51,1.15,1.76,3.81$, and $5.08 \mathrm{~cm}$ ) computed by the regular version of FIAT (gray lines) and the enhanced version of FIAT (black lines) using the baseline 119-species equilibrium chemistry model for all three arcjet simulation cases. The results again indicate that consideration of gas momentum transfer and gas kinetic energy only slightly decreases the predicted in-depth temperature. This result is obtained because the kinetic energy of pyrolysis gas is relatively small compared with other components of internal energy.

The effect of permeability variations on gas pressure, density, and kinetic energy is also studied in this group. In Figs. 11a to 11c, the gas temperature and pressure profiles at the end of each heat pulse for three permeability levels $(0.5 K, K$, and $2 K)$ are presented. The gas density and solid density distributions at the end of the heat pulse are given in Figs. 12a to 12c, and the distributions of kinetic energy density and mass flow rate are shown in Figs. 13a to 13c. An increase in permeability reduces gas pressure and density; however, it increases gas flow speed and kinetic energy. These predictions confirm that gas mass flow rate and temperature are not particularly sensitive to the variation of permeability for PICA.

A comparison of predicted temperature histories for the ninespecies finite-rate (black lines), frozen (dark gray lines), and equilibrium (light gray lines) gas chemistry models is provided in Figs $14 \mathrm{a}$ to $14 \mathrm{c}$ for the three arcjet conditions. The observed discrepancy in the PICA in-depth temperature predictions among three chemistry models mainly results from the gas phase enthalpy. This is because the predicted chemical species concentrations strongly depend on the chemistry model implemented in the code, and the gas enthalpy is a function of chemical species concentrations. Inside the pyrolysis zone, the maximum difference in predicted indepth temperature is $40 \mathrm{~K}$. For this arcjet group, the effect of uncertainty on gas phase chemistry modeling of pyrolysis gas appears to have less influence on the overall PICA thermal response as compared with the first group of flight simulations, because of the relatively thin char layer.

Figures $15 \mathrm{a}$ to $15 \mathrm{c}$ show the predicted mass fractions of $\mathrm{CO}_{2}$, $\mathrm{C}_{2} \mathrm{H}_{2}, \mathrm{CH}_{4}, \mathrm{H}_{2}$, and $\mathrm{CO}$ for nine-species finite-rate (solid lines) and nine-species equilibrium (dashed lines) chemistry models at the end of each heat pulse. The trends are similar to what was seen in group I. For all three arcjet conditions, the results of the nine-species finite-rate chemistry model indicate that the pyrolysis gas flow is at or near chemical equilibrium in the region near the front surface of PICA.

\section{Conclusions}

A special version of fully implicit ablation and thermal response code was developed. The new capabilities implemented in this version of code include the time-dependent pyrolysis gas flow momentum equation with Darcy-Forchheimer terms and the pyrolysis gas species conservation equations with a nine-species finite-rate homogeneous chemical reaction model developed specifically for the phenolic impregnated carbon ablator. The total energy conservation equation was also enhanced to reflect these additions. Various parametric studies were performed for two groups of test cases. The first group used a heating environment for a proposed Orion lunar return vehicle, and the second group used three heating environments for arcjet tests conducted at NASA Ames Research Center. The central focus of these parametric studies was to understand the effect of pyrolysis gas chemistry on the in-depth thermal response. Thus finite-rate, equilibrium, and frozen homogeneous gas chemistry models for pyrolysis gas were examined.
Results from the current parametric studies show that gas kinetic energy is a relatively small component in the internal energy balance equation, and neglecting gas kinetic energy has little negative impact on the accuracy of in-depth temperature predictions. The in-depth temperature predictions using a finite-rate or a frozen pyrolysis gas chemistry model are higher than those using a chemical equilibrium model. The results computed using a finite-rate gas chemistry model indicate that pyrolysis gas flow is at or near a chemical-equilibrium condition in the region near the front surface for all flow conditions studied in this work. Compared with the baseline model, this enhanced version of code tends to predict slightly lower temperatures in the char zone due to the effect of pyrolysis gas kinetic energy, and slightly higher temperatures in the pyrolysis zone as the result of finite-rate chemical reactions. However, overall, the differences in predicted in-depth temperatures are considered to be small. The presence of chemical nonequilibrium pyrolysis gas flow does not significantly alter the in-depth thermal response performance predicted using the chemical equilibrium gas model. Thus, the PICA/ FIAT material thermal response model developed by the Orion Thermal Protection System Advanced Development Project should be applicable for a fairly wide range of entry conditions with reasonably good accuracy.

\section{Acknowledgment}

This work was funded by the NASA Fundamental Aeronautics Program Hypersonics Project.

\section{References}

[1] Chen, Y.-K., and Milos, F. S., "Ablation and Thermal Analysis Program for Spacecraft Heatshield Analysis," Journal of Spacecraft and Rockets, Vol. 36, No. 3, 1999, pp. 475-483. doi: $10.2514 / 2.3469$

[2] Chen, Y.-K., and Milos, F. S., "Two-Dimensional Implicit Thermal Response and Ablation Program for Charring Materials," Journal of Spacecraft and Rockets, Vol. 38, No. 4, 2001, pp. 473-481. doi:10.2514/2.3724

[3] Chen, Y.-K., and Milos, F. S., "Three-Dimensional Ablation and Thermal Response Simulation System,” AIAA Paper 2005-5064, June 2005

[4] April, G. C., Pike, R. W., and Del Valle, E. G., "Modeling Reacting Gas Flow in the Char Layer of an Ablator," AIAA Journal, Vol. 9, No. 6, 1971, pp 1113-1119. doi: $10.2514 / 3.6330$

[5] Ayasoufi, A., Rahmani, R. K., Cheng, G., Koomullil, R., and Neroorkar, K., "Numerical Simulation of Ablation for Reentry Vehicles," AIAA Paper 2006-2908, June 2006.

[6] Ahn, H.-K., Park, C., and Sawada, K., "Response of Heatshield Material at Stagnation Point of Pioneer-Venus Probes," Journal of Thermophysics and Heat Transfer, Vol. 16, No. 3, 2002, pp 432-439. doi: $10.2514 / 2.6697$

[7] Martin, A., and Boyd, I. D., "Non-Darcian Behavior of Pyrolysis Gas in a Thermal Protection System," Journal of Thermophysics and Heat Transfer, Vol. 24, No. 13, 2010, pp 60-68. doi:10.2514/1.44103

[8] Bartlett, E. P., Abbett, M. J., Nicolet, W. E., and Moyer, C. B., "Improved Heat-Shield Design Procedures for Manned Entry Systems," Aerotherm, Rept. 70-15, Part II, June 1970.

[9] Knupp, P. M., and Lage, J. L., "Generalization of the ForchheimerExtended Darcy Flow Model to the Tensor Permeability Case via a Variational Principle," Journal of Fluid Mechanics, Vol. 299, Sept. 1995 pp. 97-104. doi:10.1017/S0022112095003430

[10] Tran, H., Johnson, C., Rasky, D., Hui, F., Chen, Y.-K., and Hsu, M., "Phenolic Impregnated Carbon Ablators (PICA) for Discovery Class Missions," AIAA Paper 96-1911, June 1996.

[11] Willcockson, W. H., "Stardust Sample Return Capsule Design Experience," Journal of Spacecraft and Rockets, Vol. 36, No. 3, 1999, pp. $470-474$ doi: $10.2514 / 2.3468$

[12] Milos, F. S., and Chen, Y.-K., "Ablation and Thermal Response Property Model Validation for Phenolic Impregnated Carbon Ablator," Journal of Spacecraft and Rockets, Vol. 47, No. 5, 2010, pp. 786-805. doi: $10.2514 / 1.42949$ 
[13] Marschall, J., and Cox, M. E., "Gas Permeability of Lightweight Ceramic Ablators," Journal of Thermophysics and Heat Transfer, Vol. 13, No. 3, 1999, pp. 382-384. doi: $10.2514 / 2.6451$

[14] Ward, J. C., "Turbulent Flow in Porous Media," Proceedings of ASCE, Vol. 90, 1964, pp. 1-12.

[15] Anon., User's Manual: Aerotherm Chemical Equilibrium Computer Program, Acurex Corp., Aerotherm Division, Mountain View, CA, Aug. 1981.

[16] Milos, F. S., and Chen, Y.-K., "Comprehensive Model for MultiComponent Ablation Thermochemistry," AIAA Paper 97-0141, Jan. 1997.
[17] Wright, M. J., Candler, G. V., and Bose, D., "Data-Parallel Line Relaxation Method for the Navier-Stokes Equations," AIAA Journal, Vol. 36, No. 9, 1998, pp 1603-1609. doi: $10.2514 / 2.586$

[18] Kays, W. M., and Crawford, M. E., Convective Heat and Mass Transfer, 2nd ed., McGraw-Hill, New York, 1980, pp. 355-357.

G. Russell Associate Editor 